University of Massachusetts Amherst

ScholarWorks@UMass Amherst

Doctoral Dissertations 1896 - February 2014

$1-1-1970$

\title{
Effects of visual cues on the standing body sway of males and females.
}

Seymour, Weissman

University of Massachusetts Amherst

Follow this and additional works at: https://scholarworks.umass.edu/dissertations_1

\section{Recommended Citation}

Weissman, Seymour, "Effects of visual cues on the standing body sway of males and females." (1970). Doctoral Dissertations 1896 - February 2014. 1447.

https://doi.org/10.7275/wwxt-rc14 https://scholarworks.umass.edu/dissertations_1/1447

This Open Access Dissertation is brought to you for free and open access by ScholarWorks@UMass Amherst. It has been accepted for inclusion in Doctoral Dissertations 1896 - February 2014 by an authorized administrator of ScholarWorks@UMass Amherst. For more information, please contact scholarworks@library.umass.edu. 


\title{
EFFECTS OF VISUAL CUES ON THE STANDING BODY SWAY
}

\author{
OF MALES AND FEMALES
}

A dissertation Presented

By

Seynour Weissman

Submitted to the Graduate school of the University of Massachusetts in partial fulfillnent of the requirements for the degree of DOCTOK OF PHILOSOPHY

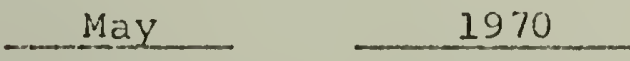

Major Subject Psvchology 
The author wishes to express his gratitude to Drs. Stanley M. Moss and John T. Danielson of the Psychology Department and Dr. Donald E. Scott of the Electrical Engineering Department for their guidance and interest in all phases of the present research. I would especially like to thank my advisor, Dr. Ernest Dzendolet of the Psychology Department for his daily direction and advice on this project and throughout the past two years.

A special note of thanks to ny wife Carol for her moral support and encouragement during this project. 


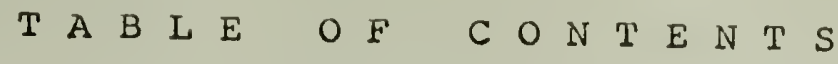

page

Acknowledgment............................

List of Figures...........................

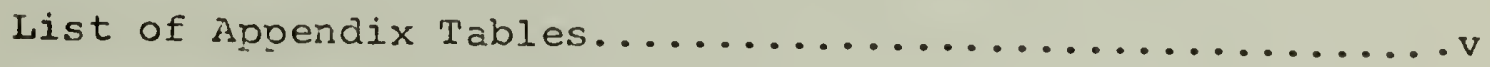

Introduction $\ldots \ldots \ldots \ldots \ldots \ldots \ldots \ldots \ldots \ldots \ldots \ldots \ldots \ldots \ldots \ldots \ldots$

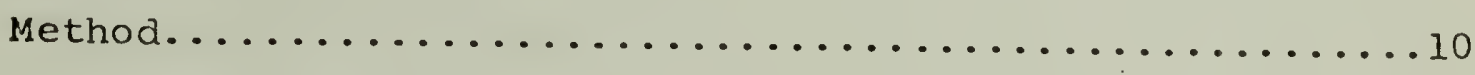

subjects.................................

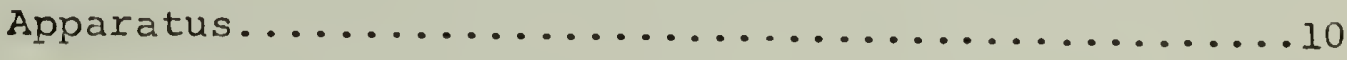

Procedure...............................

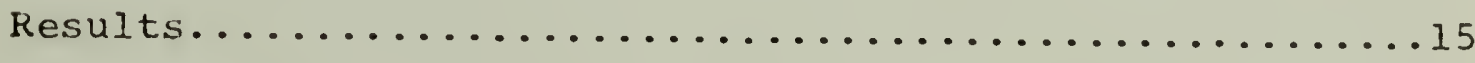

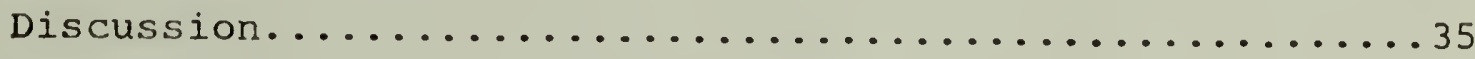

Summary $\ldots \ldots \ldots \ldots \ldots \ldots \ldots \ldots \ldots \ldots \ldots \ldots \ldots \ldots \ldots \ldots \ldots$

References..............................43

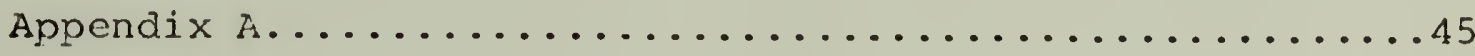

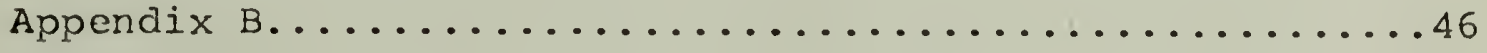


Figure

page

1 Plot of the nean lateral sway PSD's for feinale $\underline{S}$ at both eyes closed and eyes open conditions........17

2 Plot of the mean lateral sway PSD's for male $\underline{S}$ at both eyes closed and eyes open conditions...........18

3 Plot of the mean lateral sway PSD's for female $\underline{S}$ at the horizontal, vertical and diagonal rod

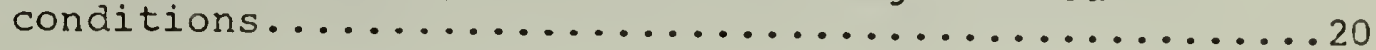

4 Plot of the mean lateral sway PSD's for male ss at the horizontal, vertical and diagonal rod conditions.2l

5 Plot of the mean lateral sway PSD's for female $\underline{S}$ s at both diagonal right and lean left conditions.......22

6 Plot of the mean lateral sway PSD's for male ss at both diagonal right and lean left conditions.......23

7 Plot of the mean lateral sway PSD's for female $\underline{S}$ at the eyes closed, eyes open, lean left, and averäged

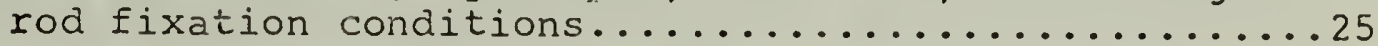

8 Plot of the mean lateral sway PSD's for male $\mathrm{Ss}$ at the eyes closed, eyes open, lean left, and avēraged

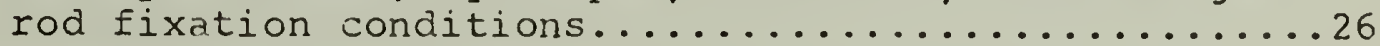

9 Plot of the mean lateral sway PSD's for both male and female $\mathrm{Ss}$ at the eyes closed condition.............28

10 Plot of the mean lateral sway PSD's for both male and fenale $\underline{s}$ s at the eyes open condition...............29

11 Plot of the mean lateral sway PSD's for both male and fenale $\underline{S}$ s at the vertical rod condition.............30

12 Plot of the mean lateral sway PSD's for both male and female $\underline{S} s$ at the horizontal rod condition...........32

13 Plot of the mean lateral sway PSD's for both male and female $\underline{s}$ s at the diagonal right rod condition.......33

14 Plot of the mean lateral sway PSD's for both male and female $\underline{s}$ at the lean left condition.................... 
$\begin{array}{lllllllllllllllll}L & I & T & \mathrm{O} & \mathrm{F} & \mathrm{A} & \mathrm{P} & \mathrm{P} & \mathrm{E} & \mathrm{N} & \mathrm{D} & \mathrm{I} & \mathrm{T} & \mathrm{A} & \mathrm{B} & \mathrm{L} & \mathrm{E}\end{array}$

Appendix

page

A Analysis of variance of lateral sway............45

B Scheffé single and multiple comparisons...........46 
In the normal process of standing, both postural and visual stimuli are involved. Postural cues include kinesthetic sensations from muscles, tendons, joints, and viscera, as well as information from the vestibular apparatus. In addition, visual stimulation provides a cue as to the main axes of the upright position, namely, the horizontal and vertical directions. All of these sources of information must be integrated to provide the individual with the corrections necessary to maintain an upright position.

One of the major difficulties in studying elements of this type of behavior by an introspective or psychophysical technique is the lack of unique sensory qualities associated with a standing oosition. Wendt (1951) described the situation as follows:

It is introspectively hard to distinguish possible vestibular from kinesthetic sensations, especially when reflexes of the trunk and limbs and autonomic systems complicate the experience, or to separate them from vision when the eyes are open.

An undoubted reason for this lack is the necessity for making very quick corrections of position in order to maintain an upright posture. Such quick responses become, in effect, unconditional reflexes.

By grouping the various factors into two categories, namely, postural and visual cues, investigators have attempted to study their relative roles in normal standing behavior. Koffka (1935) noted that when subjects in upright positions viewed a tilted mirror through a tube, they perceived the 
scene as tilted. He concluded that visual factors played the dominant role. Gibson and Mowrer (1938), usjing the same task, came to a different conclusion. They reported that the subjects never really felt themselves a part of the tilted room, and that judgment of the upright was anchored mainly to the body.

A number of studies incicated a possible compromise or interdependency between visual and postural factors. Passey and Guedry (1950) noted that subjects tended to set the perceived visual vertical in line with the true, or gravitational, vertical. Mann and Berry (1949) found that when blindfolded subjects were tilted away from the perpendicular, they could not readjust theinselves to the true vertical if they were held in the tilted position for a number of seconds. The error in readjustment was dependent both on the time in the tilted position and upon the angular value of the tilt. Mann and Dauterive (1949) discovered that postural tilt of only a few degrees caused the greatest uncertainty in perceiving the true vertical in posture. One of the most extensive studies of visual vs. postural factors was undertaken by $\mathrm{Asch}$ and Witkin (1948). In a series of four experiments, Asch and Witkin manipulated both the body position of the subject and his visual field. Both postural and visual factors could be tilted independently of one another, but in the same plane. A mirror, a luminous rod, and a tilting room were used as visual stimuli. In general, tilting of the visual cues caused 
a shift in the perceived upright in the direction of the tilt. However, the influence of the visual cues was smaller with body upright than with body tilted. In addition, the effect of the visual field upon the perceived upright tended to be stronger and more consistent the more richly articulated the field. To illustrate this point, the following mean errors were obtained with body erect and field tilted: for the luminous rod, $6.0^{\circ}$; for the room, $14,9^{\circ}$; and for the mirror, $22.0^{\circ}$. Despite these overali trends, Witkin and Asch reported large individual differences in subjects' use of visual and postural cues. Sex differences were also noted in these studies. With both tilting rod and room stimuli, women, in general, accepted the visual stimulus as the true vertical at more extreme tilts than did men. This was the case both when the subjects were upright and when they were tilted. It was concluded that the women subjects tended to be more influenced by visual than by postural factors (witkin et. al., 1954).

Werner and Wapner (1949) postulated a sensory-tonic theory to explain upright position behavior. Sensory (mainly visual input) and tonic (input from muscles) factors were believed to interact in an equivalent manner to contribute to the perception of the upright. Several experiments were undertaken to test this theory. Wapner, Werner, and Chandler (1951) studied the effects of electrical and auditory stimulation on the visual perception of the verticality of a luminous rod stinulus. While the subject made judgments, electrical 
stimulation was applied to the right or left neck muscle, or auditory to the right or left ear. With no stimulation, the subjects rotated the rod $1.4^{\circ}$ counterclockwise from the true vertical. Electrical and auditory stimulation resulted in displacement of the vertical in a direction opposite to the side stimulated. It was concluded that extravisual stimulation could affect the perception of the upright. In a second study, the effects of supported and unsupported body positions on the perceived upright was investigated (wapner, Werner, $\&$ Chandler, 1951). Subjects were tilted with and without body support, and the perceived vertical was displaced more under the unsupported than the supported condition. For botn supported and unsupported conditions, the perceived vertical displacement was larger with greater degrees of body tilt, and the direction of the perceived vertical was always opposite to body tilt orientation. The authors concluded that in both increased tilt and unsupported conditions, greater muscular involvement was present, causing a more dominant influence of body factors on the perception of the vertical. Wapner, Werner, \& Chandler (1951) also noted significant individual differences between subjects, and males and females were found to differ in their use of postural and visual cues. These differences were not explained by the authors.

In the studies previously discussed, body position was obtained through the subjects' judgments of felt and seen position. Objective measurements of the active process of 
maintaining a standing position were not employed. To this end, Miles (1921) developed the ataxiameter, an instrument to measure body sway from a static standing position. The ataxiameter was a mechanical pulley system attached to the S's head which automatically measured the amount of sway in both lateral and anterior-posterior directions. With the use of the ataxianeter, or of similar methods, a number of investigators measured subjects' sway responses with eyes opened and closed. The results of these sudies proved to be contradictory, in that some investigators (Miles, 1921; Edwards, 1942) found greater sway with blindfolded subjects, while others (Buillard \& Brackett, 1888; Niles, 1921) reported slightly better stability or less sway with eyes closed. In addition, in the eyes-open conditions, the subjects were, in most cases, not restricted to specific visual targets in varying orientations. Subjects were simply allowed to open their eyes and view the general environment of the experimental room. In an exception to this method, Travis (1945) had the subjects align a small white bead with a circle with their dominant eye. He found less sway in this condition than with eyes closed.

More recently, Dzendolet (1963) and Bensel \& Dzendolet (1968) have elaborated on the ataxiameter method and developed a technique to specify standing sway more accurately. Body sway, both antero-posterior and lateral, is measurea by means of strain gauges under a stable platform on which the subject 
stands. A power spectral density analysis (PSD) of the subjects' sway presents the average power contained in specified frequency bands of the sway waveform. The usual way of displaying this measure is by means of a plot of PSD against frequency. With blindfolded subjects, Bensel \& Dzendolet (1968) found that power in standing sway was distributed unequally among a number of frequency bands below $1.00 \mathrm{~Hz}$, with most of the power lying between 0.0 and $0.4 \mathrm{~Hz}$, regardless of sway direction. The greatest amount of sway was found in the antero-posterior direction. On the basis of the frequencies at which peaks of power occurred, it was found that different patterns emerged, and subjects could be grouped into different sway types (Dunstone \& Dzendolet, 1964; Bensel \& Dzendolet, 1968). A possible factor underlying these sway types, namely, a height-weight relationship, was investigated, but no clear result was noted (Bensel, Dzendolet, \& Meiselman, 1968). Bensel, Dzendolet, \& Meiselman (1968) also found that lateral sway was less correlated with measures of height-weight body characteristics than was sway in the anter-posterior direction. This relative independence (Pearson $\underline{r}$ correlations of .01 for men and. 10 for women, as compared to .42 and. 41 for the antero-posterior direction) of body characteristics indicated that lateral sway might be the more appropriate response measure of the vestibular motor system. In addition, significant differences were found between male and female lateral sway patterns, but not in the antero-posterior direction. 
Male and female antero-posterior patterns tended to overlap and did not show the independence between the groups noted in lateral sway (Bensel, Dzendolet, \& Meiselman, 1968; Dzendolet, Personal communication).

The separate role of visual factors in the maintenance of the normal process of standing has not been adequately defined. In the past, the presentation of visual cues in various orientations were correlated with subjective reports of felt and seen vertical and tilted body position. objective measurements of changes in body position as a function of specific visual stimuli were not employed. Those studies that did employ more objective ataxiameter measurements reported contradictory findings for open- and closed-eyes conditions, and failed to specify appropriate visual stimuli quantitatively.

To isolate the role of vision in standing behavior, the nature and limits of the postural variable must be defined. To this end, the concept of body sway seems to serve the purpose. Concerning the nature of body sway, the mechanisms underlying this response are presently not clear. Most studies indicate some form of control through the vestibular apparatus. Studies of electrical stimulation of the vestibular apparatus have shown changes in both sway amplitude and frequency as a function of different characteristics of the electrical input (Dzendolet, 1963; Bensel, 1967). Spiegal \& Scala (1943) found that cathodic stimulation of the vestibular apparatus in cats increased muscle tonus of the forelegs, and 
anodic stimulation decreased it. Thus, according to this theory, sway would be produced by the simultaneously increased muscular tonus on one side of the body, coupled with decreased tonus on the other (Dzendolet, 1963). However, the specific vestibular anatomical site affected by electrical stimulation and its neuronal interaction with the kinesthetic motor system has not been completely established (Bensel, 1967). Nevertheless, body sway does represent a valid postural response measure. Body sway can be viewed as a waveform with given ranges of frequency and amplitude. PSD analysis of this waveform is a method to quantify this constantly changing response output and present it in a meaningful fashion. With this measure as a postural baseline, deviations both in pattern and magnitude of sway as a function of specific visual stimuli can be evaluated.

Body sway responses of humans were analyzed using a control systems approach. Sway output was assumed to be a non-recurring waveform rather than a periodic one. Systems analysis of such a signal involves the power spectral density (PSD) and the autocorrelation ( $A C F$ ) functions. According to Milsum (1966), the latter is a mathematical measure used to define a waveform or when it is constantly changing in an unpredictable manner, and the former is a transformation of it. PSD is expressed as power per unit frequency, where the "power" unit is proportional to signal amplitude squared. Thereforc, frequency is on the abscissa, and the PSD value on 
the ordinate. The PSD is expressed in arbitrary units. For convenience, a dB scale of the PSD is used with an arbitrary reference level of unity. The total power in a signal equals the area which results from integrating the curve over all frequencies. This power is generally expressed in watts in systems where the waveform can be calibrated.

The autocorrelation function identifies waveform periodicities by correlation of output with itself at a later time. Tine shift is on the abscissa and the value of the correlation is on the ordinate. The power spectral density is the Fourier transform of the autocorrelation function, and contains the same mathematical information. However, they accentuate different aspects of a waveform, since the PSD is in the frequency domain, and the autocorrelation is in the time domain (Milsum, 1966).

The purpose of this investigation was to analyze, by use of the PSD, the effects of visual cues on the lateral standing sway of males and females. 
Subjects. These were six male, and six female students or employees of the University of Massachusetts. Those selected had $20 / 20$ vision, corrected or uncorrected. They also had no history of head injury, of muscle or bone injury to the legs of feet, of fainting spells, or of a recent illness. At the time of the experiment, the subjects (Ss) were not taking any medication, with the possible exception of multipurpose vitamins.

Apparatus. The Ss stood on a square wooden platform, approximately $68 \mathrm{~cm}$. along each side and $2 \mathrm{~cm}$. thick. The platform was supported at the center of each side by the ends of four horizontally positioned steel bars of rectangular cross section which extended under the platform. The platform was also firmly fastened to these bars by a machine screw through each bar. The other ends of the supporting bars were rigidly fastened to a framework of welded steel positioned below the platform, and which was approximately the same dimensions as the platform. Strain gauges were on two opposite bars, and were connected as elements of a wheatstone bridge circuit. This arrangement allowed recording of lateral sways when $\underline{S}$ was positioned properly. The outputs of the bridge circuit were led into preamplifiers (Hewlett-Packard 2470A), and were recorded on one channel of a multichannel FM tape recorder $(\lambda . R$. Vetter \& Co., Model A). No sensation of movement or rocking of the platform occurred if $\underline{s}$ shifted his weight (Bensel \& Dzendolet, 1968; Bensel, Dzendolet, \& 
Meiselman, 1968).

The visual stimulus was presented by use of a luminous line or rod, $39 \mathrm{in.}$ long and $\mathrm{l}$ in. wide, set in a flat black background (44" $\left.\times 44^{\prime \prime}\right)$. The rod subtended visual angles of $33^{\circ} 24^{\prime}$ (length) and $0^{\circ} 24^{\prime}$ (width). The rod was placed in various orientations, $5 \mathrm{ft}$. in front of $\underline{s}$. The center or pivot point of the rod was always placed at s's $^{\prime}$ eye level. For each target orientation, the luminance of the rod was .63 mL as measured by a light meter (Honeywell Pentax).

Procedure. The following visual conditions were employed:

1. S blindfolded (Eyes Closed).

2. Eyes open, lights on with $\underline{s}$ viewing general laboratory environment (Eyes Open).

3. Luminous rod horizontal (Horizontal).

4. Luminous rod vertical (Vertical).

5. Luminous rod displaced $45^{\circ}$ in clockwise direction from the vertical set point (Diagonal-Right).

6. Eyes closed, lean left (Lean Left).

Pilot data indicated that during presentation of the diagonal targets, S's sway contained a body lean component that was in a direction opposite to the orientation of the visual target. In other words, Ss leaned left while viewing diagonal right targets. To this end, during the presentation of diagonal right targets, the average lean of five pilot Ss

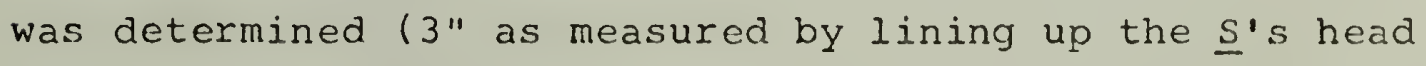
position with a scale located on a wall behind the $\underline{S}$ ). During 
the lean condition, in the present experiment, each $\underline{S}$ assumed the "normal" standing position on the platform with eyes closed. The experimenter (E) then moved or leaned the $\underline{S}$ a distance of three inches to $\underline{s}^{\prime} s$ left, with $\underline{S}$ still maintaining the original foot or stance position. The $\underline{S}$ was asked to maintain this lean position as well as he could with his eyes closed. In this way, it was hoped that the Iean left condition would serve as a control for lean behavior which resulted from the presentation of the diagonal-right target. If leaning were the primary component of S's sway behavior during the presentation of a diagonal-right target, sway for the two conditions would be expected to be similar. If leaning were not the prine component, differences between the conditions would seem likely to occur.

At the start of each session, the $\underline{S}$ was shown the platform, asked to remove his shoes, and was seated. The following instructions were then read to $\underline{\mathrm{S}}$ :

Your task during this experiment is to stand on the platform. Stand without moving your feet or legs once their position has been set, and also without moving your hands, arms, or head. Please clasp your hands together and let them hang limply in front of you. Do not stand rigidly as if at attention. It is important that you relax. But relax without moving your feet or legs, your arms or your head. Also keep your weight evenly distributed on both legs.

After each trial, you will be given a five minute rest period. Are there any questions?

For all rod fixation conditions, i.e., with eyes open, $\underline{S}$ was told to fixate on the center or pivot point of the luminous rod. For each of these conditions, the luminous rod 
was the only visible object in the darkened room.

For each condition, $\underline{S}$ was helped to assume the proper position on the platform, with heels together and feet spread at about $45 \mathrm{deg}$ to one another. For all eyes-open conditions, $\underline{S}$ was shown the rod fixation point. Once positioned, the recordings were begun immediately, and $\underline{S}$ remained in position for $4 \mathrm{~min}$. Only the sway during the period from $0 \mathrm{~min}$. to $4 \mathrm{~min}$. was recorded and examined in this experiment. After each condition trial, the $\underline{S}$ was allowed to sit and rest for approximately $5 \mathrm{~min}$. while the stimulus was changed.

Each $\underline{S}$ was tested in a one day session. Each of the six visual conditions were presented according to their position in a six cell Latin Square. The experimental design was a Latin Square with one between-variable of the form:

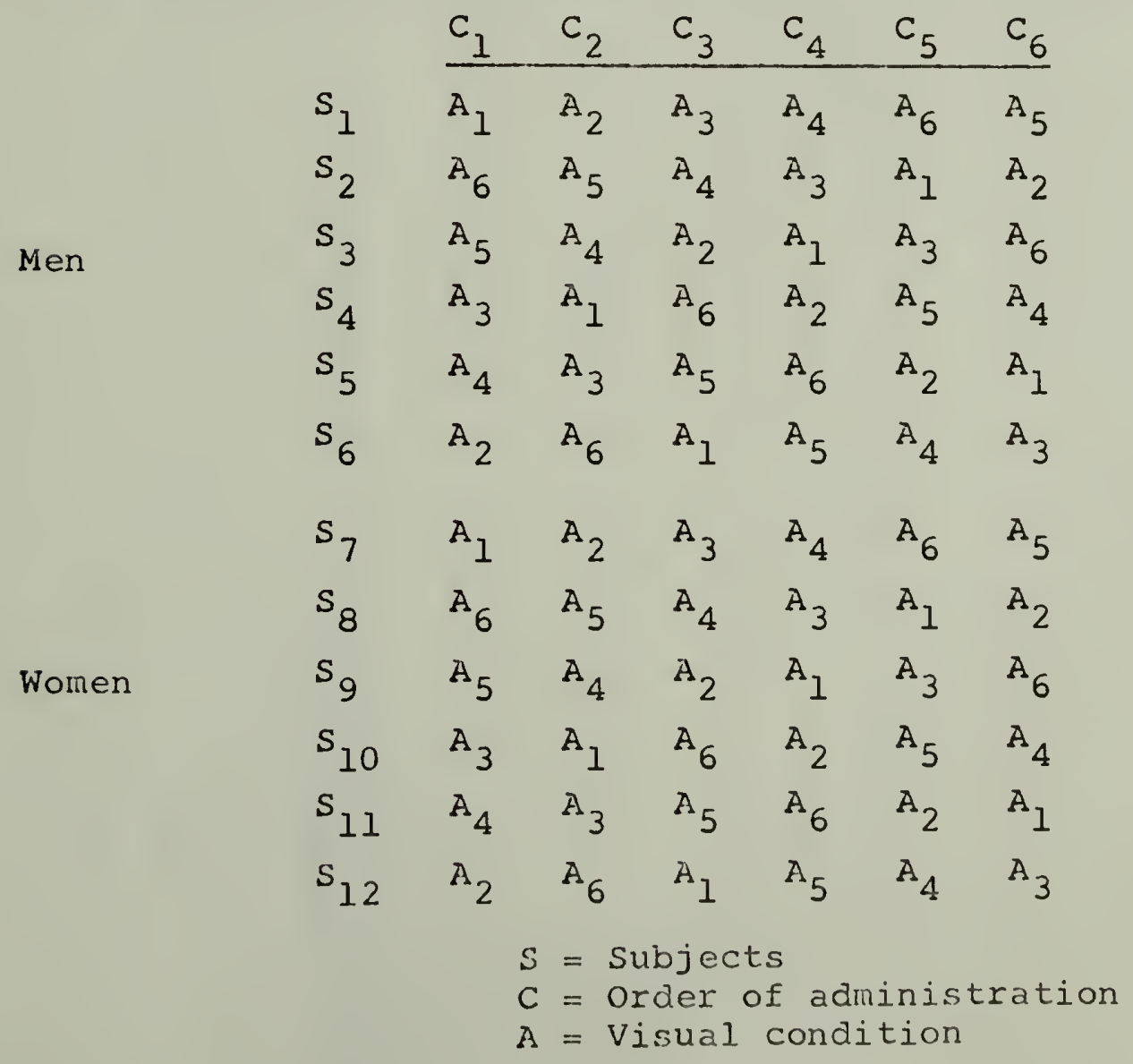


The tape recorded data was converted to digital form and sampled every $0.2 \mathrm{sec}$, using an analog-to-digital converter and a PDP-8/I computer. This procedure gave approximately 1200 data points for the $4 \mathrm{~min}$. period. The converted data, in punched paper tape form, served as an input to a time sharing terminal of the University of Massachusetts CDC 3600 digital computer. An autocorrelation function ( $A C F$ ) was computed first. The PSD function was obtained via the computer as Fourier transform of the ACF. Following that, various analyses of variance were computed manually. The raw data for the analyses of variance were the values of total power in the waveform for each $\underline{S}$. Total power was obtained by suming over the PSD values at each frequency computed and multiplying this sum by the frequency increment, .05 Hz. These calculations were carried out automatically by the computer program. An upper limit of $1.0 \mathrm{~Hz}$ was used because little additional power was contributed above that frequency. Autocorrelation functions and PSD's were obtained for all Ss, individually. To obtain information regarding the effects of the visual stimulus conditions on the frequency of sway output, mean PSD's were obtained by summing over $\underline{S}$. These mean PSD's were plotted as a function of frequency for each of the visual conditions. 


\section{R E S U L T S}

An analysis of variance, using total power in the waveform, was performed. The analysis of variance was a Latin Square design with one between variable of the form: $\underline{S}$ (males $(1-6)$, females $(1-6)$ ) by visual condition (eyes closed, vertical, horizontal, diagonal right, lean left, and eyes open). For a more detailed analysis, single and multiple comparisons of the above variables, using total power data, were also performed. These comparisons were conducted with the use of scheffe's multiple comparison method (Myers, 1967. Pp. 326-347). The analysis of variance tables are presented in Appendix A, and Scheffé's comparisons in Appendix $B$.

To obtain information regarding the effects of the visual cues on the frequency of sway output, mean PSD's were obtained by suming over $\underline{S}$. It is these mean PSD's which are presented here as most relevant to the purposes of the present experiment, since they allow the frequencies represented in the sway to be readily identified. The ACF's will not be presented since they contain the same information as the PSD's, but in a different form. Furthermore, only the power in the sway lying at frequencies from 0.0 through $1.0 \mathrm{~Hz}$ will be presented since power at the frequencies beyond $1.0 \mathrm{~Hz}$ was negligible.

The analysis of variance performed on the sway data yielded four significant sources of variance. These were Visual Conditions $(F(5,40)=6.69, \underline{p}<.001), \operatorname{sex}(F(11,40)=$ 6.94, $\mathrm{p}<.001)$, Effect of Latin Square Rows $(F(5,40)=4.56$, 
$p<.01)$, and first order interaction of Latin Square Rows by $\operatorname{Sex}(F(5,40)=15.65, p<.001)$.

\section{Visual Conditions}

Figs. 1 through 8 are the PSD curves for the visual conditions, plotted separately for each sex.

Eyes Open vs. Eyes Closed. The source of variance for the comparison between eyes open and eyes closed conditions for both females $(F(5,40)=.40, \underline{p}>.10)$ and males $(F(5,40)=$ $.51, \underline{p}>$ was not significant.

For both sexes, mean PSD's were generally lower in the eyes open than eyes closed conditions. For female $s$ s, overall mean PSD's (Fig. I) obtained with eyes open were lower than those for the eyes closed condition. Mean PSD's (Fig. 2) for male Ss were also lower at the eyes open than eyes closed conditions, with the exception of two frequencies $(.05$ and $.10 \mathrm{~Hz})$, where the reverse situation was noted.

Horizontal, Vertical, and Diagonal. In general, there was little difference between the horizontal, vertical, and diagonal conditions, for both female and male Ss. The sources of variance for the comparisons between the horizontal, vertical, and diagonal conditions, for both females and males, were not significant. The following comparisons were made: for female Ss, Vertical vs. Horizontal $(F(5,40)=.82, \underline{p}>.10)$, Vertical vs. Diagonal $\left(F(5,40)=1.16, \underline{\underline{p}}^{2} .10\right)$, and Horizontal vs. Diagonal $(\mathrm{F}(5,40)=.03, \mathrm{p}>.10)$, and for male Ss, Vertical vs. Horizontal $(F(5,40)=.20, \underline{p}>.10)$, Vertical vs. 


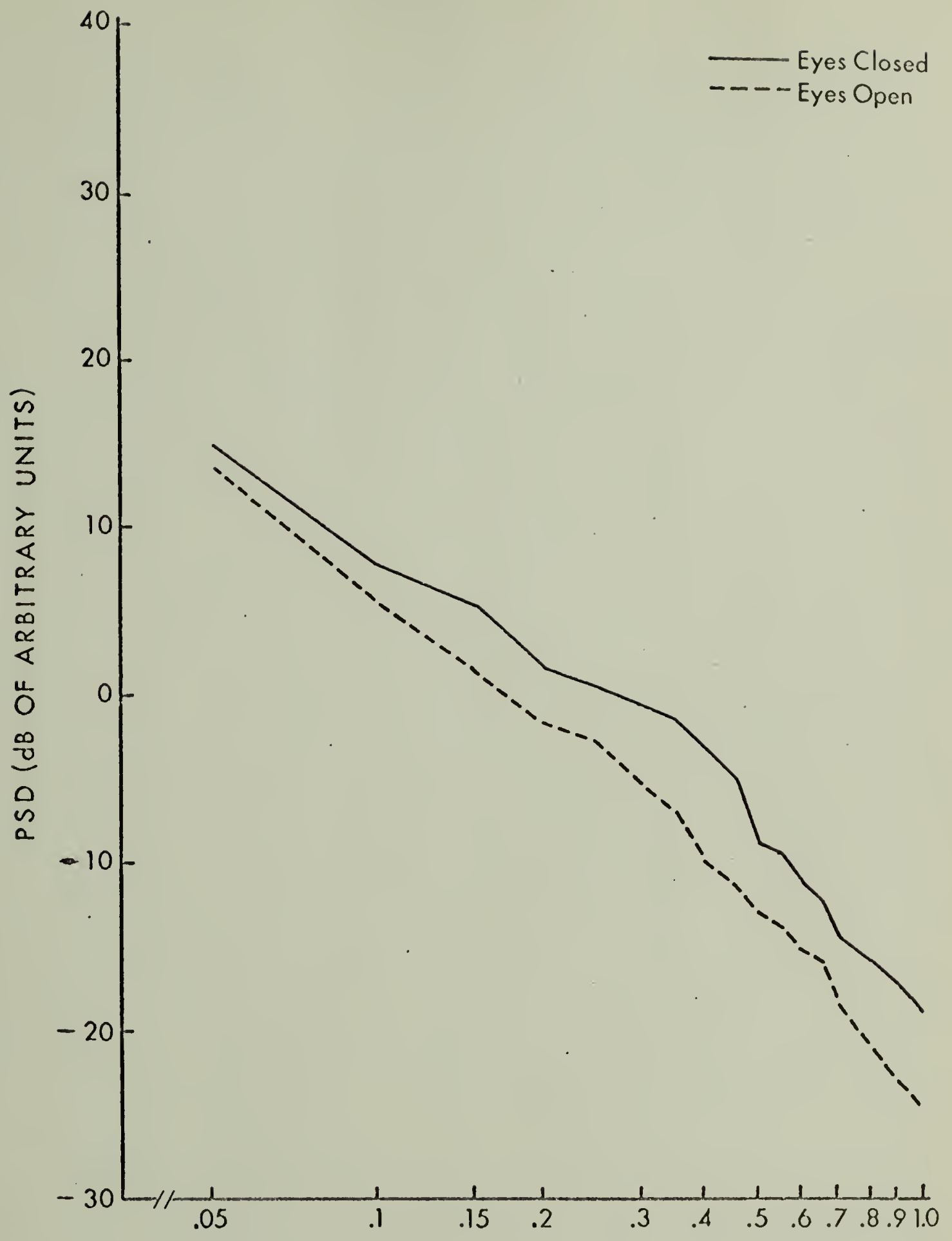

SWAY FREQUENCY $(\mathrm{Hz})$

Figure 1. plot of the mean lateral sway PSD's for female Ss at both eyes closed and eyes open conditions. 


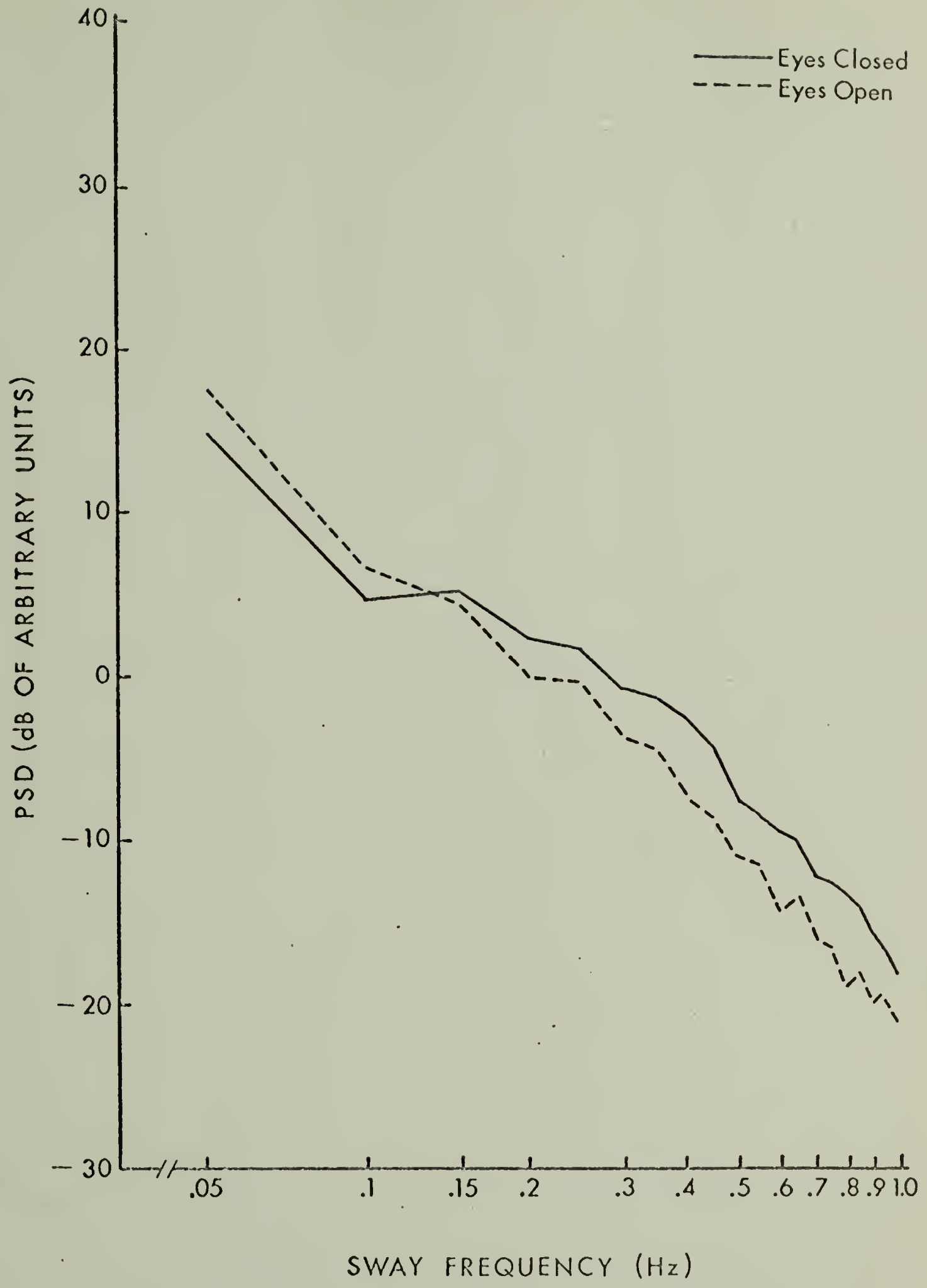

Figure 2. Plot of the mean lateral. sway PSD's for male Ss at both eyes closed and eyes open conditions. 
Diagonal $(F(5,40)=1.45, \underline{p}>.10)$, and Horizontal vs. Diagonal $(F(1,40)=.57, \underline{\mathrm{p}}>.10)$.

A plot of mean PSD's for female $\underline{S} s$ at the horizontal, vertical, and diagonal conditions (Fig. 3) revealed very little differences between the three conditions. It should also be noted that the three curves were so close as to almost appear superimposed over each other.

For male Ss, mean PSD curves (Fig. 4) for the three rod fixation conditions indicated greater overall power differences than for female S.S. The mean PSD's in the horizontal condition were generally lower than the vertical condition, which in turn was lower then the diagonal condition.

Lean Left and Diagonal Right. For both female $(F(5,40)=$ $6.92, \mathrm{p}<.001)$ and male $(F(5,40)=7.70, \mathrm{p}<.001)$ S.s, the source of variance for the comparison between the lean and diagonal conditions was significant. For female $\underline{S}$, the plot of mean PSD'S (Fig. 5) obtained in the diagonal condition indicated lower overall power than in the lean condition. Power ranged from $+24.0 \mathrm{~dB}($ at $.05 \mathrm{~Hz})$ to $-15.0 \mathrm{~dB}$ (at $1.0 \mathrm{~Hz}$ ) in the lean condition and from $17.0 \mathrm{~dB}($ at $.05 \mathrm{~Hz}$ ) to $-20.0 \mathrm{~dB}($ at $1.0 \mathrm{~Hz})$ in the diagonal condition.

Similarly, mean PSD's (Fig. 6) for male ss were lower in the diagonal than lean conditions. However, power for both diagonal and lean conditions was, in general, higher for the male than for femaie Ss. Power, for the male $\underline{S} s$, ranged from $+28.0 \mathrm{~dB}($ at $.05 \mathrm{~Hz})$ to $-11 \mathrm{~dB}($ at $1.0 \mathrm{~Hz})$ in the lean 


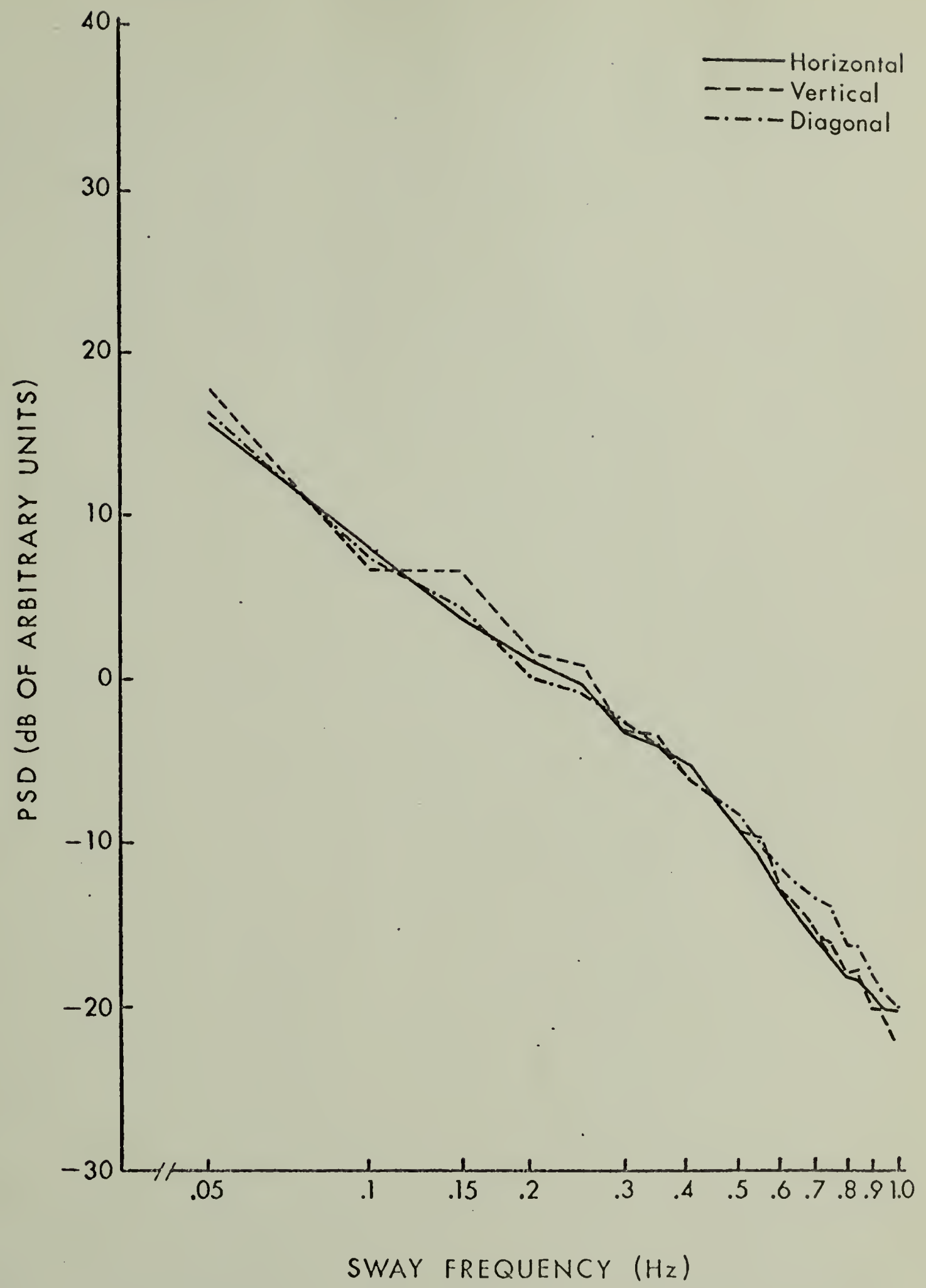

Figure 3. Plot of the mean lateral sway PSD's for female S.s at the horizontal, vertical and diagonal rod conditions. 


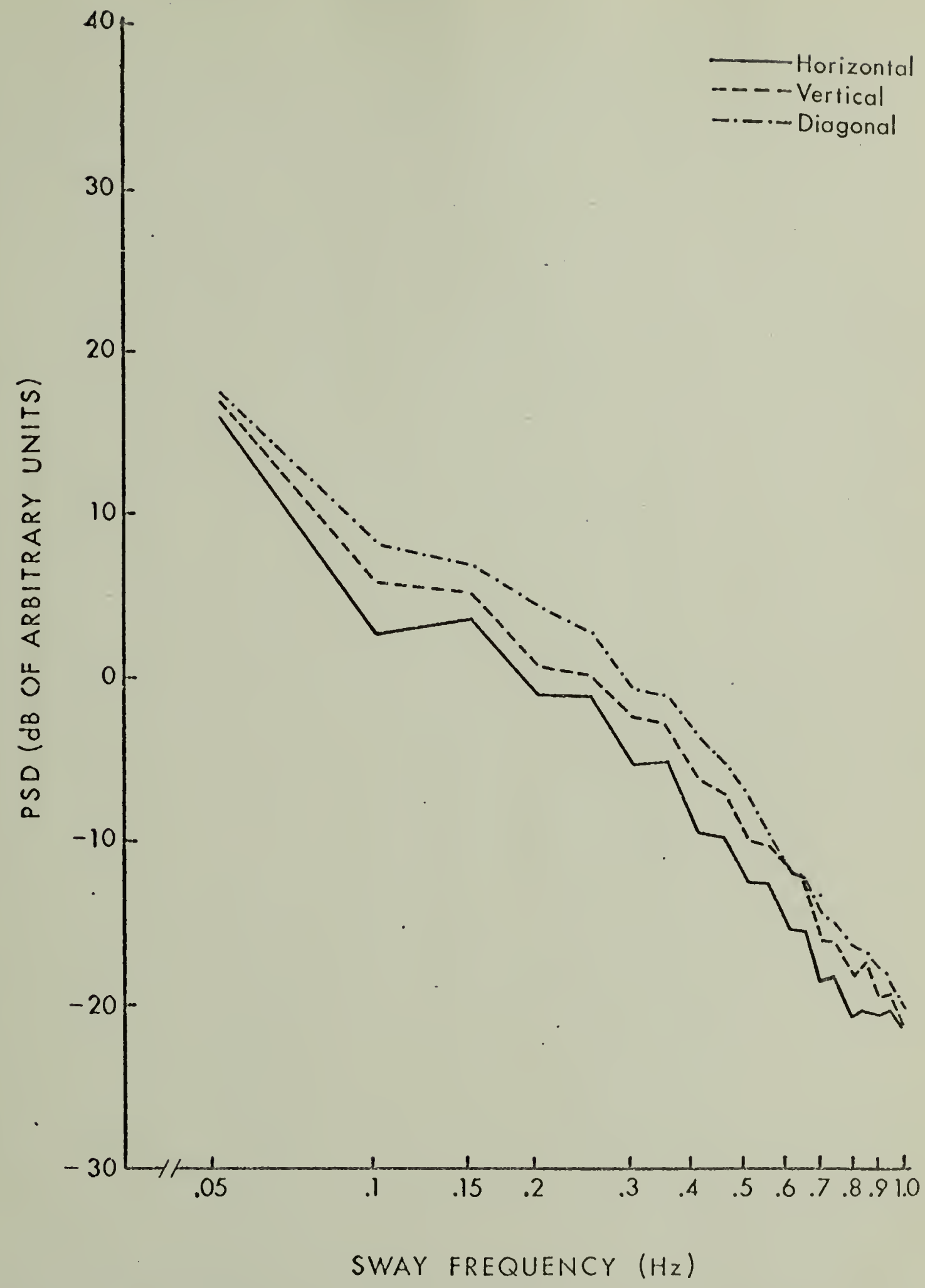

Figure 4. Plot of the mean lateral sway PSD's for male ss at the horizontal, vertical and diagonal rod conditions. 


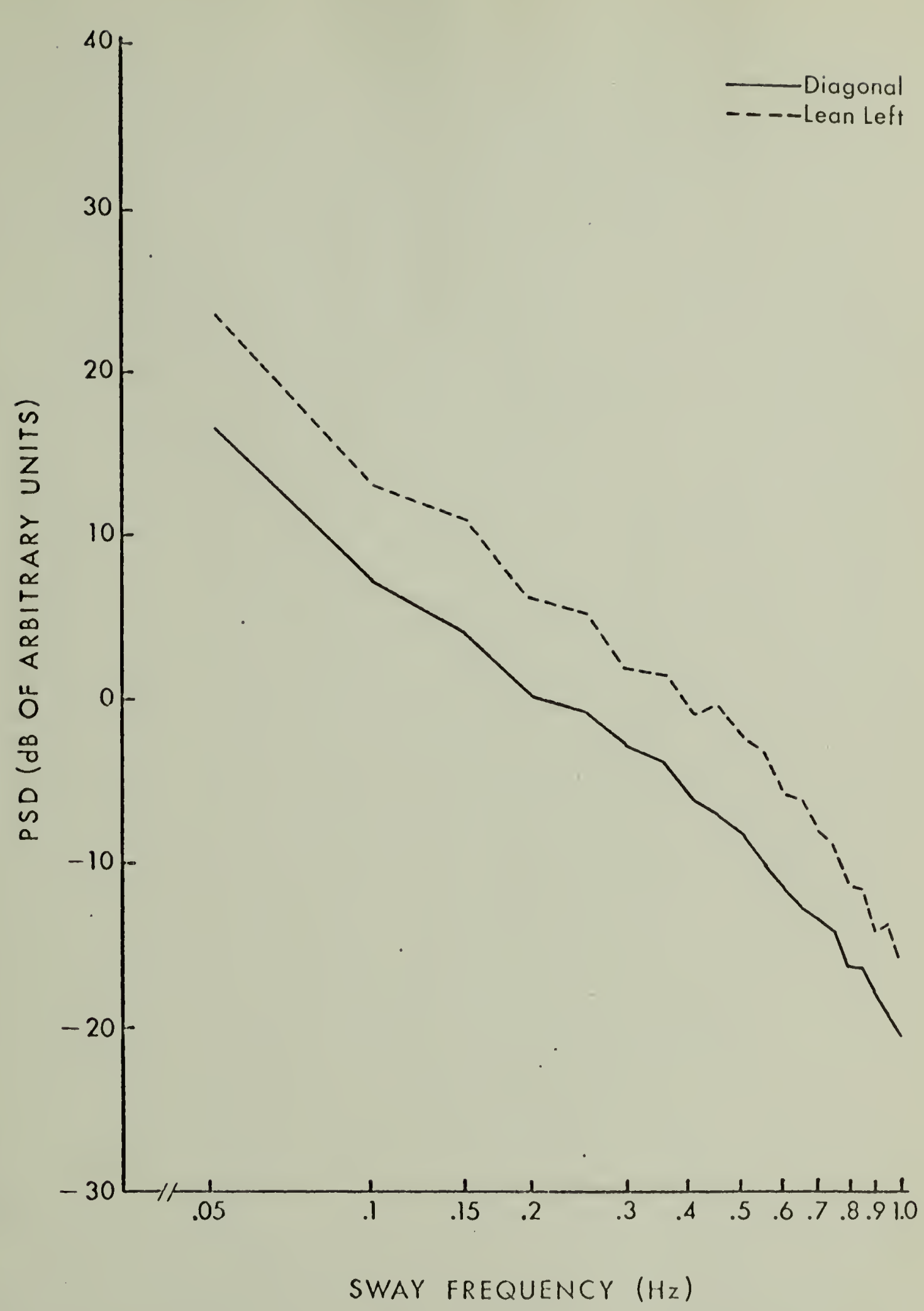

rigure 5. plot of the mean latera? sway PSD's for femaln Ss at both diagonal right and lean left conditions. 


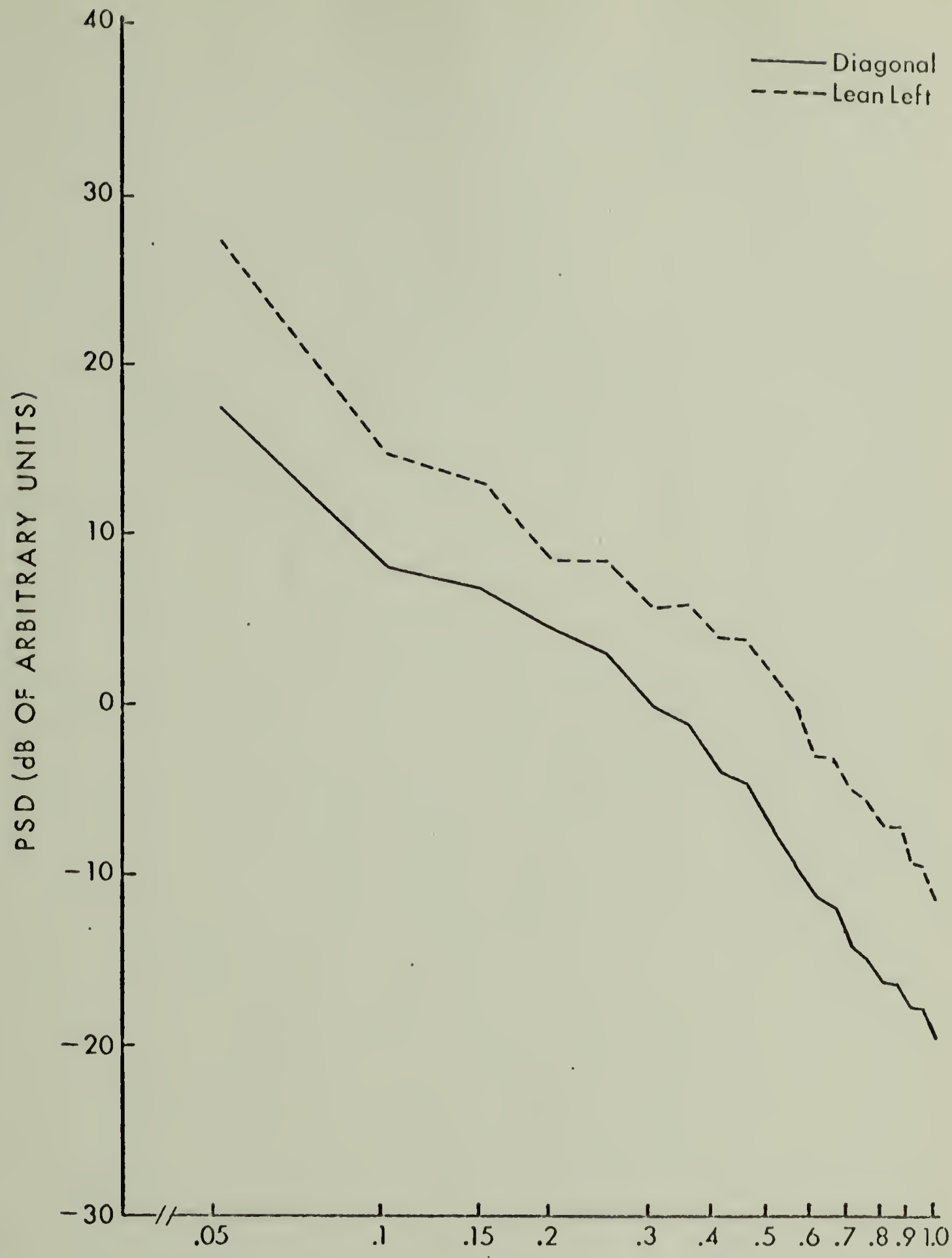

SWAY FREQUENCY $(\mathrm{Hz})$

Figure 6. Plot of the mean lateral sway PSI's for male Ss at both diagonal right and lean left conditions. 
condition and from $+18.0 \mathrm{~dB}($ at $.05 \mathrm{~Hz}$ ) to $-19.5 \mathrm{~dB}$ (at 1.0 $\mathrm{Hz}$ ) in the diagonal condition.

To try to attain a more complete understanding of the effects of visual targets on body sway, mean PSD's for all conditions were plotted for both females (Fig. 7) and males (Fig. 8). In Figs. 7 and 8 the three visual rod conditions (vertical, horizontal, and diagonal) were not plotted separately due to the extrenely small differences found between them. Instead, an average of the PSD's for each $\underline{S}$ for the three conditions, for males and females, was employed. In this way, the average score was used as an indicator of the three rod fixation conditions. Thus, mean PSD's for the following conditions were plotted in Figs. 7 and 8: Eyes Open, Eyes Closed, Lean Left, and averaged Horizontal, Vertical, and Diagonal conditions (rod fixation).

For female Ss (Fig. J), there seemed to be very little difference between the eyes closed and averaged rod fixation conditions. However, mean PSD's revealed that overall power was lower in the eyes open condition than any of the other three conditions. In like manner, overall power was highest in the lean condition. The source of variance for the comparison between the three averaged rod fixation conditions and the lean left condition $(F(5,40)=7.36$, $\underline{F}<.001)$ was significant. Sources of variance for the comparisons between the averaged rod fixation condition and either eyes open $(F(5,40)=1.44, \underline{P}>.10)$ or eyes $\operatorname{closed}(F(5,40)=.18$, $\underline{p}>.10)$ were not significant. 


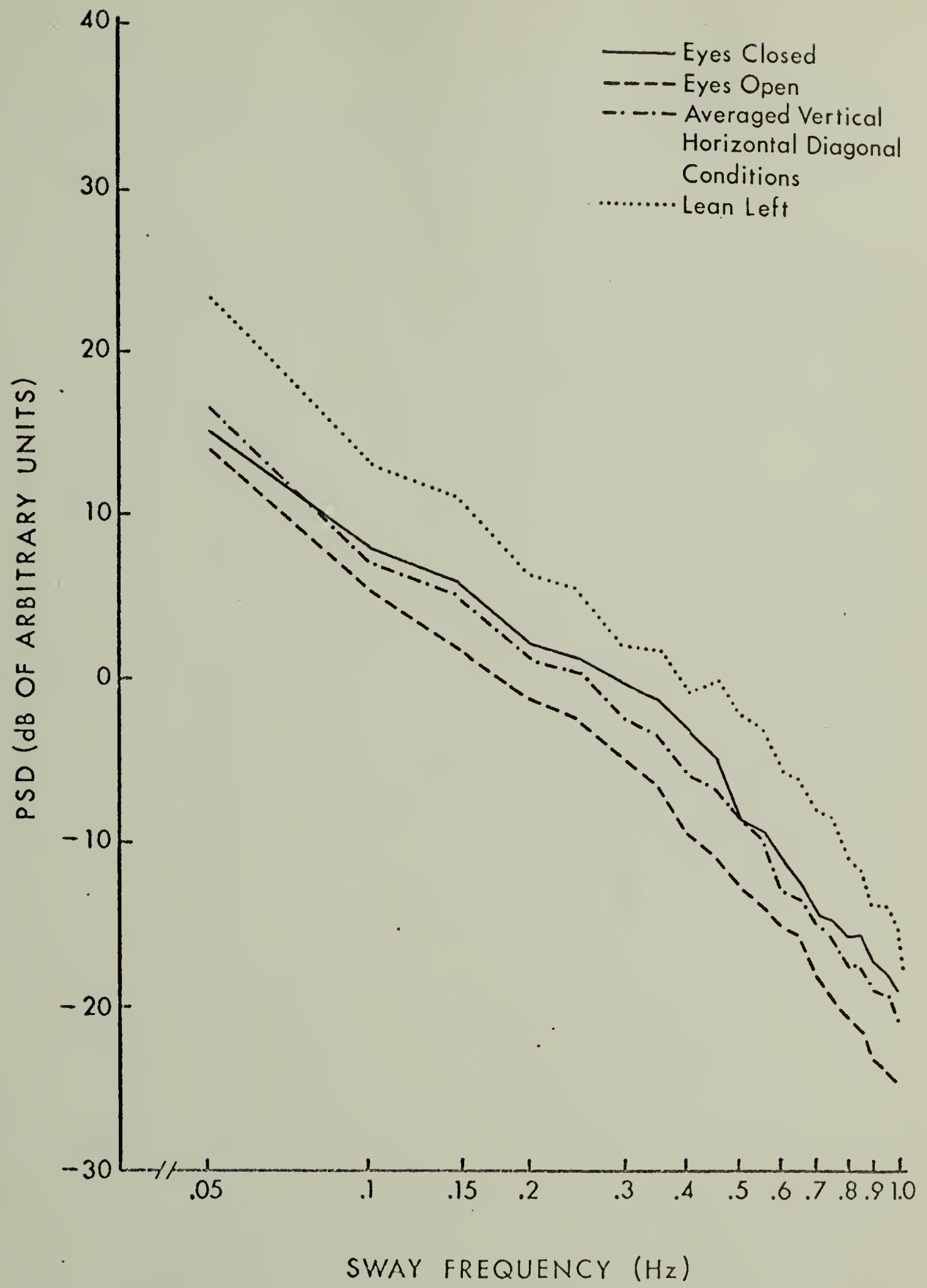

Figure 7. Plot of the mean lateral. sway PSD's for female Ss at the eyes closed, eyes open, lean left, and averaged rod fixation conditions. 


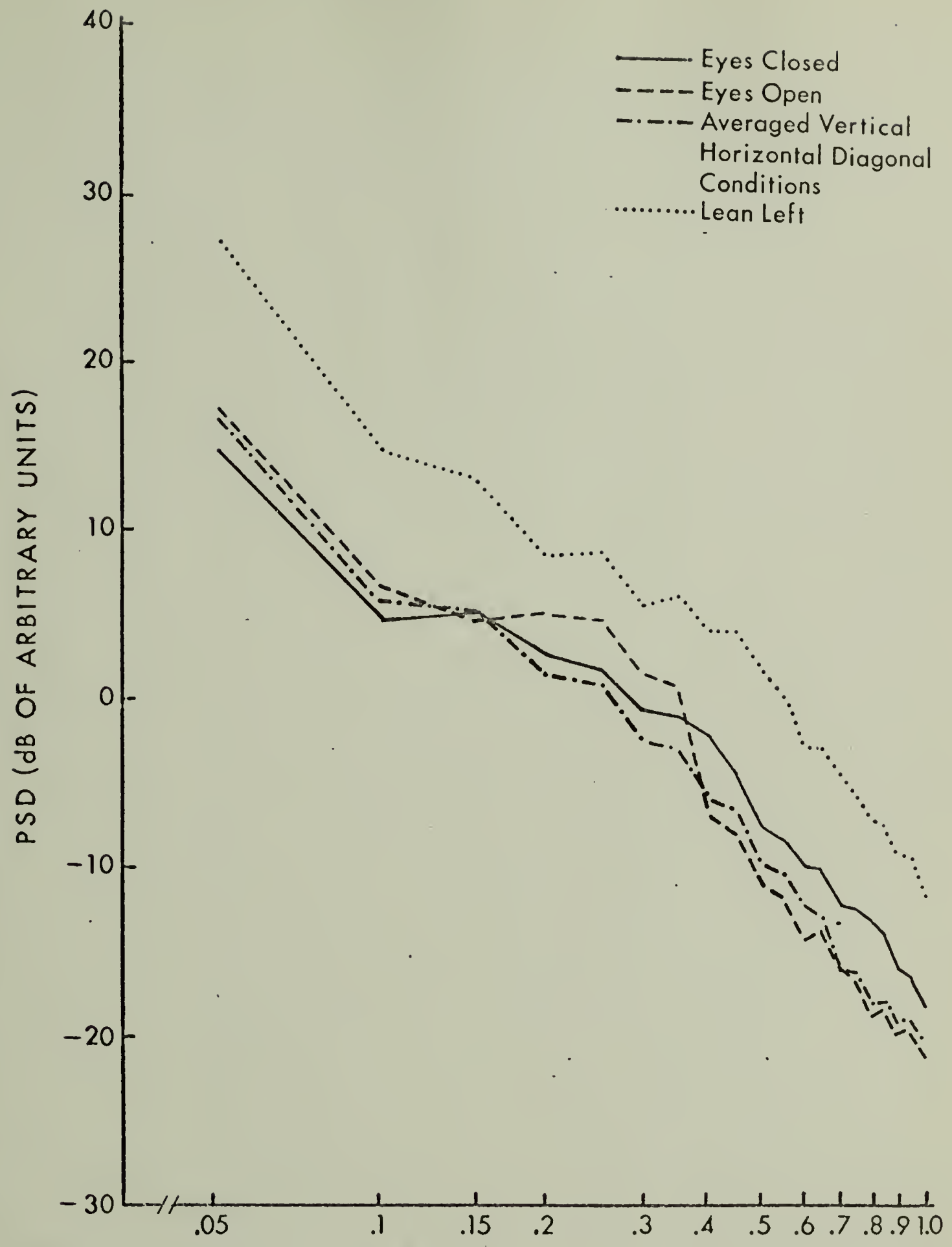

\section{SWAY FREQUENCY $(\mathrm{Hz})$}

Figure 8. plot of the mean lateral sway PSD's for male S.s at the eyes closed, eyes open. lean left, and averaged rod fixation conditions. 
The plot of the mean PSD's for male Ss (Fig. 8) revealed little difference between the eyes open, eyes closed, or averaged rod fixation conditions. However, mean PSD's indicated highest overall power at the lean condition. Sources of variance for the comparisons between the averaged rod fixation condition and either eyes open $(F(5,40)=.075$, $\underline{p}>.10)$ or eyes closed conditions $(F(5,40)=1.32, \underline{p}>.10)$ were not significant. As with female ss, the source of variance for comparison between the averaged rod fixation condition and lean left $(F(5,40)=17.61, \mathrm{p}<.001)$ was significant.

\section{Sex Differences}

To better delineate the effects of the factor of sex, mean PSD's for both male and female Ss were plotted for each visual condition (Figs. 9-14).

Eyes Closed. There seerned to be little difference between the mean PSD's for male and fernale $\underline{S}$ in the eyes closed condition (Fig. 9). The source of variance for the comparison between males and females in the eyes closed condition $(F(5,40)=.032, \underline{p}>.10)$ was not significant.

Eyes Open. At all frequencies, mean PSD's in the eyes open condition (Fig. 10) were lower for female then for male Ss. The source of variance for the comparison between male and female Ss at the eyes open condition $(F(5,40)=1.28$, $\underline{p}>.10)$ was not significant.

Vertj.cal Rod. A plot of the mean PSD's (Fig. II) seemed 


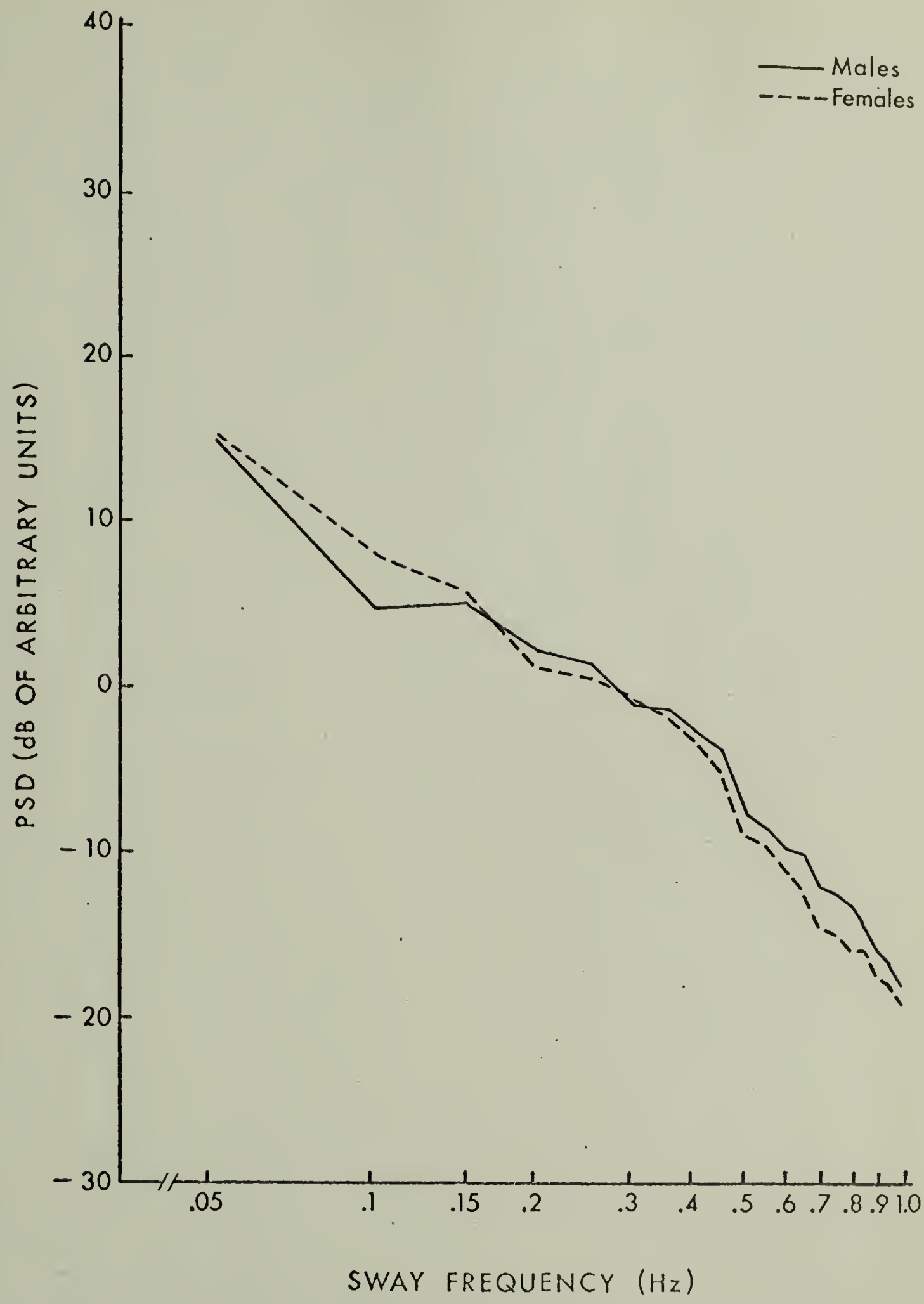

Figure 9. Plot of the mean lateral sway FSD's for both male and female $\underline{S}$ s at the eyes closed coniltion. 


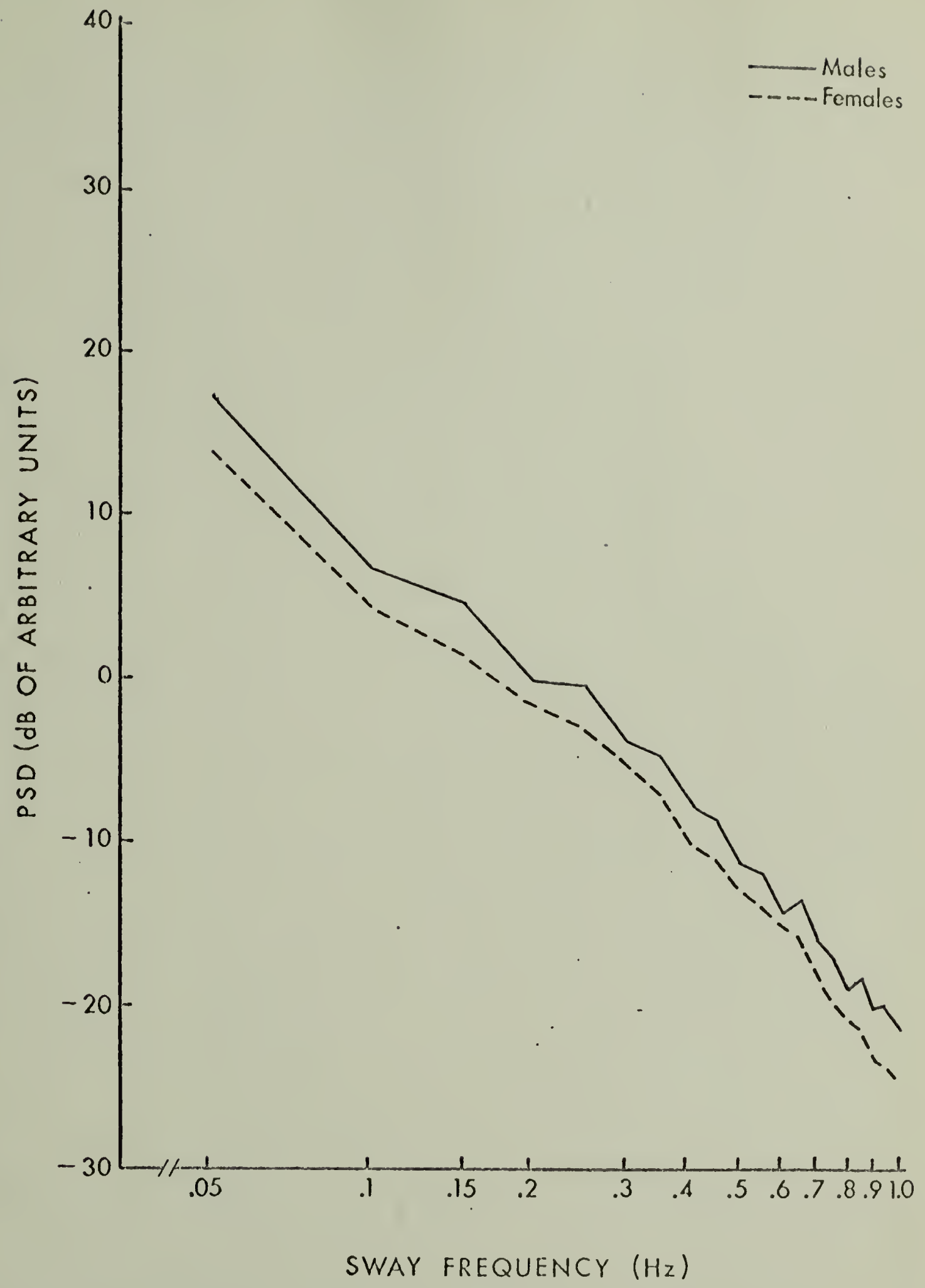

Figure 10. plot of the mean lateral sway PSD's for both male and female $\underline{S}$ s at the eyes open condition: 


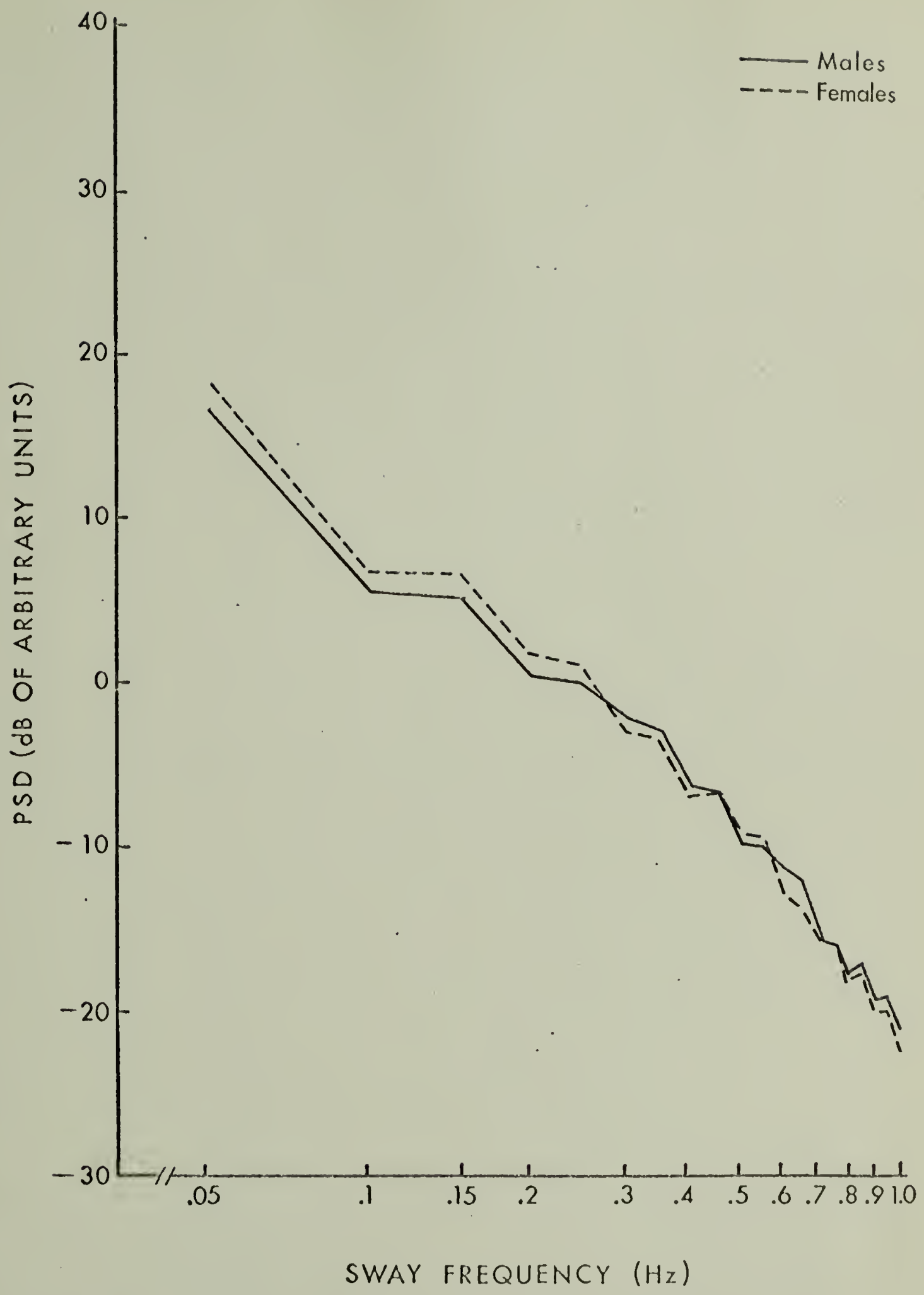

Figure 11. Plot of the mean lateral sway PSD's for both male and female $\underline{S}$ at the vertical rod condition. 
to indicate little difference between male and female $\underline{S}$ s in the vertical rod condition. The source of variance for the comparison between the male and female $\underline{S} s$ in the vertical condition $(F(5,40)=.067, \underline{p}>.10)$ was not significant.

Horizontal Rod. Mean PSD's (Fig. 12), in general, reveal slightly lower power for males than for females at the horizontal rod condition. The source of variance for the comparison between male and female $\underline{s}$ s at the horizontal rod condition $(F(5,40)=.49, \underline{p}>.10)$ was not significant.

Diagonal. Right. The plot of mean PSD's (F'ig. I3) revealed slightly less power for female $\underline{S} s$. The comparison between male and female $S s$ at the diagonal condition $(F(5,40)=1.83$, $\underline{p}>$.10) indicated a non-significant source of variance.

Lean Left. The source of variance for the comparison between male and female $\underline{S}$ at the lean left condition $(F(5,40)=$ 2.11, $\underline{p}<.101$ was significant. The plot of the mean PSD's (Fig. 14) showed that overall power was lowex for female than male Ss. For males, power ranged from $27.5 \mathrm{~dB}($ at $.05 \mathrm{~Hz}$ ) to $-11.0 \mathrm{~dB}($ at $1.0 \mathrm{~Hz}$ ) and for females, from $23.5 \mathrm{~dB}$ (at .05 Hz) to $-15.0 \mathrm{~dB}($ at $1.0 \mathrm{~Hz})$. 


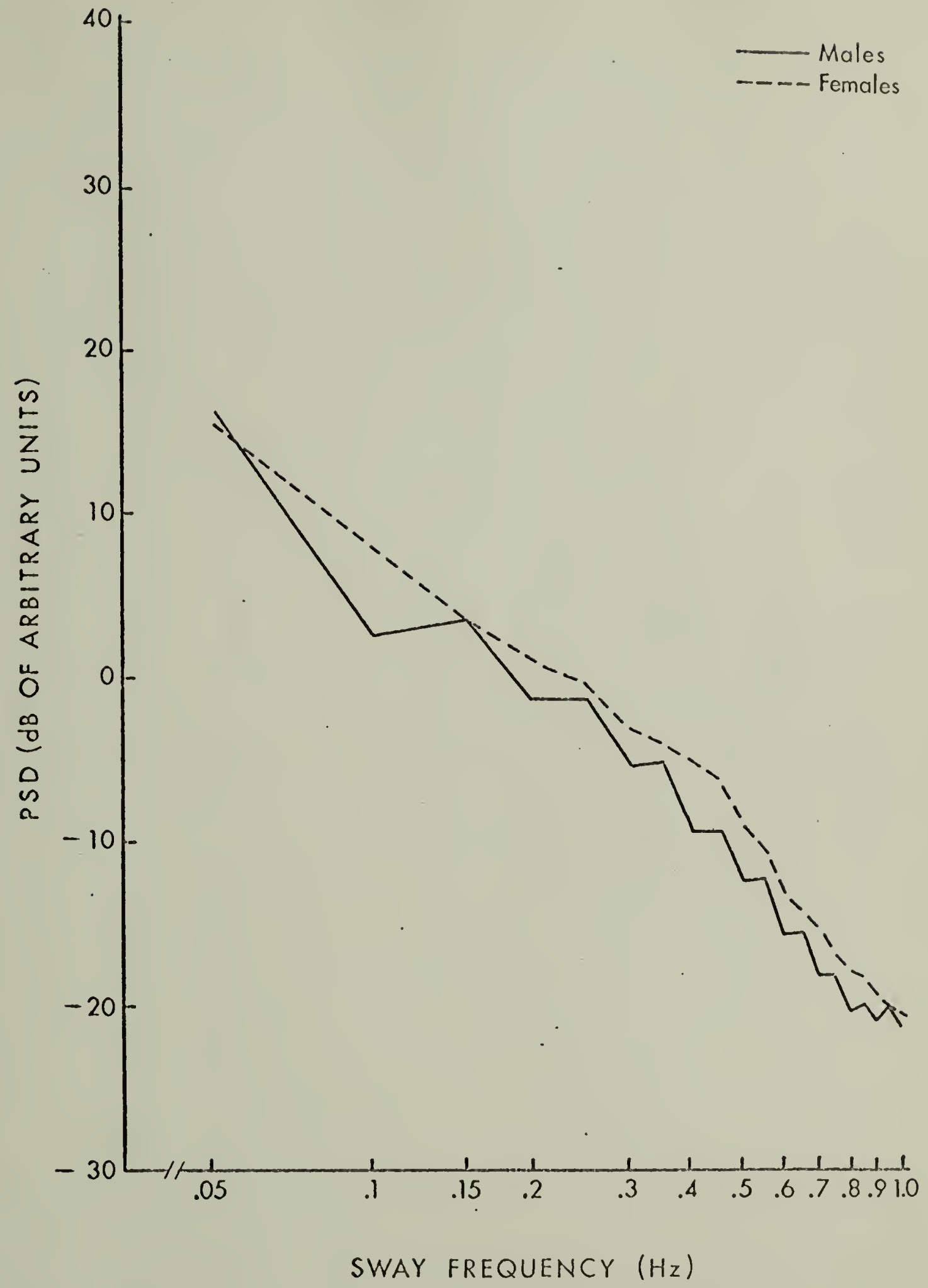

Figure 12. Plot of the mean lateral Sway PSD's for both male and female $\underline{S}$ s at the horizontal rod condition. 


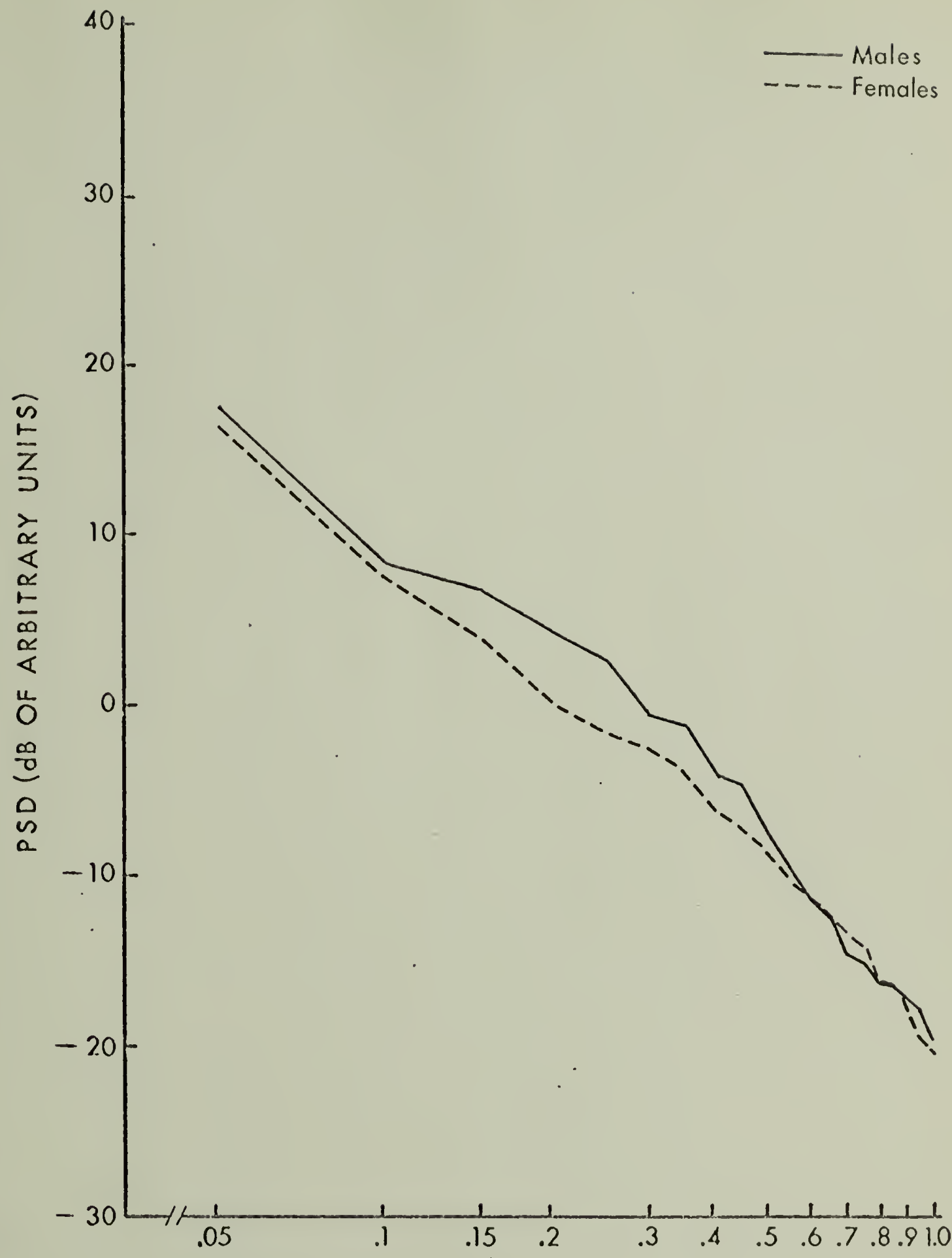

SWAY FREQUENCY $(\mathrm{Hz})$

Figure 13. Plot of the mean lateral sway PSD's for both male and female $\mathbf{S} s$ at the diagonal right rod condition. 


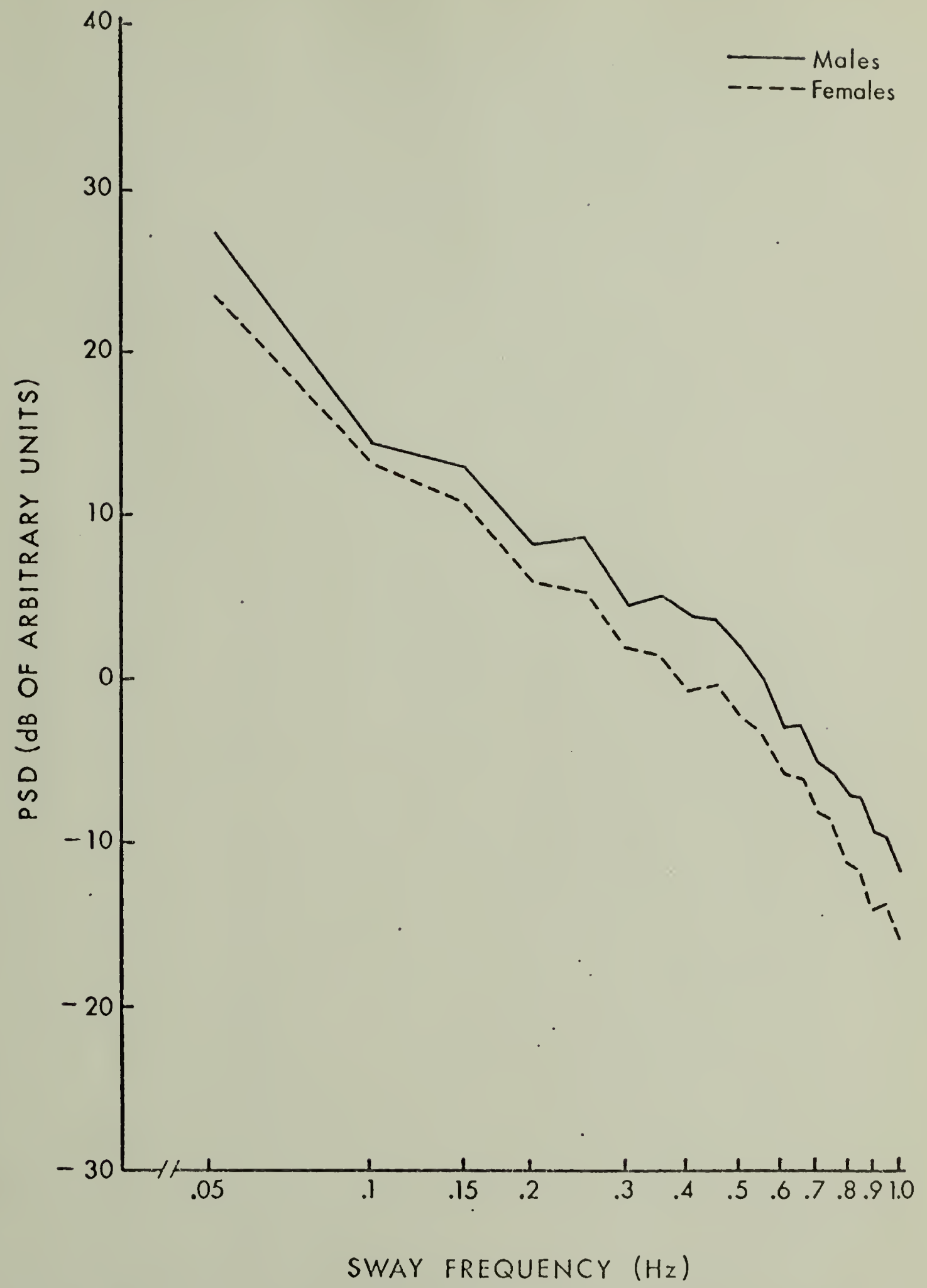

Figure 14. plot of the mean lateral sway PSD's for both male and female $\underline{S}$ s at the lean left condition. 


\section{I S C U S S I O N}

The presence of visual cues as employed in the present experiment seemed to have little effect on body sway, as measured by PSD. Of all the experimental variables, only the non-visual condition of body lean showed any indication of statistical significance. Visual fixation of a rod, in various orientations (vertical, horizontal, and diagonal) did not seem to change static body equilibrium. Figs. 7 and 8 , in which the results of all visual conditions were plotted, showed that there was little difference in mean PSD's between the eyes closed and averaged visual rod fixation target conditions. In addition, body sway was not markedly affected by a change in rod orientation. This result was most dramatically seen in Fig. 3. For female $\underline{S}$, overall power, in terms of mean PSD's, were essentially equal for the three rod orientation positions. For male $\underline{S}$, there seemed to be greater differences in mean PSD's between the three rod conditions than for females, but here again these findings were not significant.

While statistical significance was noted only for the lean condition, the other major variables tended to show certain interesting trends. For example, the eyes open condition, for both sexes, seemed to have the greatest visual effect on standing body sway. As noted in Figs. 1 and 2 , S.s seened to be more stable (lower mean PSD's) in the eyes open than eyes closed conditions. These results tend to support the findings of a number of investigators (Miles, 1921; Edwards, 1942) who with the use of the ataxiameter method 
found greater sway with eyes closed than opened.

The difference between the eyes open and closed conditions held for both sexes, but was more pronounced for the female $\underline{S}$. In line with this point, female $\underline{S}$ s also showed less overall power (lower mean PSD's) in the eyes open condition than in the three rod fixation conditions (Fig. 7 ). This finding was not as clear for male Ss (Fig. 8), in which little difference was noted between these conditions.

Regarding the variable of sex, females tended to be more stable or show less overall power than males in a number of conditions. In the eyes open (Fig. 10) and diagonal (Fig. 13) conditions lower mean PSD's were noted for fenales than for males at most frequencies. In like manner, power was markedly lower in the lean condition for the female $\underline{S}$. The results of the eyes closed (Fig. 9), vertical (Fig. 11), and horizontal (Fig. 12) conditions revealed little differences between the sexes. Of interest was the difference between the sexes in the eyes closed and eyes open conditions. With eyes closed, power was essentially the same for both sexes. With eyes open, female $\underline{S}$ s tended to have lower overall power than males. These findings are in accord with those of Witkin et. al., (1954), who, with a more subjective measure of body position, noted that women Ss tended to be more influenced by visual than by postural factors.

The similarity between male and female $S$ s in the eyes closcd condition is of interest because of its apparent 
contradiction to the previous literature. Recently, it was reported that with eyes closed, females tended to sway with less overall power than males (Dzendolet, personal communication). A possible reason for the contradiction in findings might be due to differences in the amount of time sway data was sampled. Dzendolet's findings were based on $1 \mathrm{~min}$. of data while in the present study 4 min. samples were employed.

In the lean condition, significantly lower power was noted for feinales than males. This finding seems to lend some support to those theories advocating the factor of body type or structure as a prime determiner of sway (Bensel, Dzendolet \& Meiselman, 1968). In other words, with visual factors eliminated, males and females with obvious differences in bone and muscle structure, exhibited markedly different sway patterns, in terms of overall shifts in PSD level. Thus, in the lean condition, body type would seem to be one of the major factors in the results obtained.

Concerning the lean condition, a question was raised as to possibility of body lean being a major component of lateral sway during the presentation of the diagonal rod target. With the addition of a lean condition, it was hoped that this possibility could be controlled, and its contribution to body sway evaluated. As noted in Figs. 5 and 6 , for both male and female $\underline{S}$, there was significantly less overall power (lower mean PSI's) in the diagonal than lean conditions. Thus, body lean, as defined in this study, did not seem to be a major 
contributor to overall power of body sway, during presentation of the diagonal rod target. However, it should be noted that the body lean condition was, in effect, only a partial control. Preliminary observations of sway behavior during presentation of the diagonal target revealed that $\underline{s}$ leaned an average of three inches from the starting equilibrium position. However, this lean was usually not maintained for more than 2 or 3 seconds, and $\underline{S}$ oscillated back and forth between various stages of lean and the zero or starting position. Thus, only a portion of body lean behavior (placing the $\underline{s}$ three inches from the starting position) was used in the present lean left condition. For practical considerations, the various stages of lean and their oscillations were found difficult to simulate and employ in a control condition.

Another aspect of the findings which is of interest concerns the distribution of power among the frequency bands below $1.0 \mathrm{~Hz}$. As noted in Figs. 1-14, most of the power, for all visual conditions, was found between 0.0 and $0.5 \mathrm{~Hz}$. After $0.5 \mathrm{~Hz}$, power decreased rapidly, and was negligible at frequencies beyond $1.0 \mathrm{~Hz}$. These results coincide with Bensel \& Dzendolet (1968) who reported a similar distribution of power for male Ss with eyes closed. Thus, the distribution of power seened not to be changed markedly with visual input. The trends of those changes due to visual cues seemed instead to involve an overall change in PSD level rather than shifts in any peaks of the PSD to new frequencies. 
The eyes open condition seemed to be the most salient visual cue involved in static equilibrium. In the eyes open condition, both male and female Ss tended to be more stable, i.e., showed less power, than with eyes closed. However, the visual fixation of a rod in any of three orientations did not seem to appreciably affect the PSD pattern. Both males and females swayed much the same while fixating the rod, as with eyes closed. The situation involved in the eyes open condition would seem to deserve further study. During the eyes open condition, the visual stimuli involved were contained in the general environment of the experimental room viewed by $\underline{S}$. It is thought that increased effort should be directed to try to isolate the rnajor elements of this visual environment. The type and number of these visual cues and their effect on body sway would seem to be logical questions to begin such an investigation.

Data from the present study tends to show that females employ visual cues to a greater extent than males to maintain stability. Results reveal sinilarities between the sexes in the eyes closed condition, but less overall power for fenales in the eyes open condition. Differences between the sexes, in the rod fixation conditions, were negligible.

In conclusion, in the normal process of standing, the visual system of normal $\underline{S}$ s seems to have little influence in the maintenance of this position. Postural cues from muscles, tendons, joints, and the labyrinthine system seem to provide 
enough information to stabilize the body in a static equilibrium condition. In more active or dynamic conditions, i.e., body balancing, walking, running, etc., greater visual input to the postural system might be needed due to the increased postural coordination required. To this end, studies similar to the present investigation should be undertaken, to test the influence of the visual syster on various aspects of dynamic equilibrium. In adaition, the probably more salient role of the visual system in labyrinthine-defective $\underline{S}$ s should also be noted. In situations in which the labyrinth is impaired, greater use of the visual system would be expected to compensate for the partial or total loss of postural control. Preliminary findings with labyrinthine-defectives seem to support this contention (Ek, Personal comrnunication). Labyrinthine-defectives tended to show nore stability or less overall power in the eyes open than closed conditions, and this separation was considerably greater compared to non-defective s.s. 
In a standing position, six male and six female ss were exposed to the following visual conditions: eyes closed, luminous rod vertical, luminous rod horizontal, luminous rod diagonal right, eyes closed - body lean left, and eyes open with view of experimental room. Each $\underline{S}$ was tested in a single session, with the six conditions presented according to their position in a Latin Square design. Each trial consisted of a 4 min. stimulus presentation period followed by 5 min. of rest. The response measure, recorded on one channel of a tape recorder, was whole body sway in the lateral direction. This measure was analyzed using the autocorrelation, the power spectral density, and analyses of variance.

The conclusions from the present study were:

1. Lateral sway was only slightly affected by visual cues.

2. Visual fixation of luminous lines in various orientations did not differ significantly from eyes closed conditions, in their effect on lateral sway. In addition, little differences were noted in lateral sway as a function of rod orientation.

3. Ss tended to exhibit greatest stability llowest overall power) in the eyes open condition. This difference was more marked for female than male sis.

4. In general, female $\underline{s}$ s tended to be more stable (less overall power) than male $\underline{S}$, and this difference was most evident in the eyes open and lean conditions.

5. Most of the power in is' sway was between 0.0 and 
$0.5 \mathrm{~Hz}$, whether or not $\underline{S}$ were being visually stimulated.

6. Those differences noted in body sway as a function of visual conditions were of the nature of overall changes in PSD level rather than any shifts of specific peaks of the PSD to new frequencies. 
Asch, S. E. c Witkin, H. A. Studies in soace orientation. I. perception of the upright with displaced visual fields. Journal of Experjmental Psychology, 1948, 38,

Asch, S. E., \& Witkin, H. A. Studies in space orientation. II. perception of the upright with displaced visual fields and with body tilted. Journal of Experimental psychology, $1948,38,455-477$.

Asch, S. E., \& Witkin, H. A. Studies in space orientation. ITI. perception of the upright in the absence of a visual field. Journal of Experimental Psychology,

Asch, S. E., \& Witkin, H. A. Studies in space orientation. IV. further experiments on perception of the upright with displaced visual fielas. Journal of Experimental Psychology, 1948, 38, 762-782.

Bensel, $C . K$. I control systems analysis of electrically induced body sway. Unpublished doctoral dissertation, University of Massachusetts, 1967.

Bensel, C. K., \& Dzendolet, E. Power spectral density analysis of the standing sway of males. Perception and Psychophysiology, 1968, 4, 285-288.

Bensel, C. K., Dzendolet, E., \& Meiselman, H. L. Body sway during long-term standing and as affected by pure tones. Perception and Psychophysiology, 1968, 4, 171-174.

Buillard, W. N., \& Brackett, E. G. Observations on the steadiness of the hand and static equilibrium. In W. R. Miles, Static equilibriurn as a useful test of motor control. Journal of Industrial Hygiene, 1921, 3, 316-361.

Dzendolet, E. Sinusoidal electrical stimulation of the human vestibular apparatus. Perceptual and Motor skills, 1963, $17,171-185$.

Dumstone, J.J., \& Dzendolet, E. Types of objective electrical vestibulograms. Perceptual and Motor Skills, 1964, 19. 899-904.

Edwards, A. S. The measurement of static ataxia. American Journal of Psychology, 1942, 55, 171-188.

Gibson, J. J., \& Mowrer, O. H. Determinants of the perceived vertical and horizontal. Psychological Review, 1938, 45, $300-323$. 
Koffka, K. Gestalt psychology. New York: Harcourt Brace, 1935.

Marn, C. W., \& Berry, N. H. The perception of the postural vertical. II. visual factors. Joint Report No. 5, Tulane University \& U.S.N. School of Aviation Medicine, Pensacola, Florida, 1949.

Mann, C. W., \& Dauterive, J. H., Jr. The perception of the postural vertical. I. the modification of non-labyrinthine cues. Journal of Exoerimental Psychology, 1949, 39, 538-547.

Miles, W. R. Static equilibrium as a useful test of motor control. Journal of Industrial Hygienc, 1921, $3,316-361$.

Milsum, J. H. Biological control systens analysis. New York: MCGraw-Hili, Inc. , 1966 .

Myers, J. I. Fundamentals of experimental design. Boston: Allyr and Bacon, 1966.

Passey, G. E., \& Guedry, F. E., Jr. The perception of the postural vertical. III. adaptation effects in four planes. Joint Report iNo. 6, Tulane University \& U.S.N. School of Aviation Medicine, Pensacola, Florida, 1949.

Spiegal, E.A., \& Scala, N. P. Response of the labyrinthine apparatus to electrical stimulation. Archives of otolaryngology, 1943, 38, 131-138.

Travis, R. C. An experimental analysis of dynamic and static equilibrium. Journal of Experimental Psychology, 1945, $35,216-234$.

Wapner, S., Werner, H., \& Chandler, K. A. Perception: I. Effect of extraneous stimulation on the visual percention of verticality. Journal of Experimental Psychology, 1951 , $42,341-345$.

Wendt, G.R. Vestibular functions. In S. S. Stevens (Ed.), Handbook of Experimental Psychology. New York: Wiley, 1951. Pp. 1191-1223.

Werner, H., Wapner, S., \& Chandler, K. A. Experiments on sensory-tonic field theory of perception: II. Effect of supported and unsupported tilt of the body on the visual perception of verticality. Journal of Experimental Psychology, 1951, 42, 346-350.

Witkin, H. A., Lewis, H. B., Hertzman, M., Machover, K., Meissner, P. P., \& Wapner, s. Personality through percention. New York: Harper, 1954. 
$\begin{array}{lllllllllllllllll}A & P & P & E & N & D & I & X & A\end{array}$

ANALYSIS OF VARIANCE OF LATERFL SWAY

$\begin{array}{lrccc}\text { SV } & \text { df } & \text { SS } & \text { MS } & \text { F' } \\ \text { Rows } & 5 & 105.91 & 21.18 & 4.56 \underline{p}<.01 \\ \text { Sex } & 1 & 32.20 & 32.20 & 6.94 \underline{\underline{p}}<.001 \\ \text { Rows x Sex } & 5 & 363.07 & 72.61 & 15.65 \underline{\underline{p}}<.001 \\ \text { Visual Conditions } & 5 & 155.28 & 31.06 & 6.69 \underline{\underline{p}}<.001 \\ \text { Colurns } & 5 & 17.08 & 3.41 & .73 \\ \text { Visual Conditions x Sex } & 5 & 21.81 & 4.36 & .94 \\ \text { Sex x Colurns } & 5 & 16.25 & 3.25 & .70 \\ \text { Residual } & 40 & 185.82 & 4.64 & \end{array}$


$\begin{array}{llllllllllllll}A & P & P & E & N & D & I & X & B\end{array}$

SCHEFE''S SINGLE AND MULTIPIJE COMPARISONS

Comparison $\mathrm{SV}^{\mathrm{T}}$

df

F

Visual Conditions

Eyes open vs. eyes closed

$\begin{array}{ll}\text { males } & 5,40 \\ \text { females } & 5,40\end{array}$

Vertical vs. Horizontal

$$
\begin{aligned}
& \text { males } \\
& \text { females }
\end{aligned}
$$

$5,40 \quad .20$

$5,40 \quad .82$

Vertical vs. Diagonal
males
5, 40
1.45
fermales
5,40
1.16

Horizontal vs. Diagonal
males
5. 40
.57
females
5,40
.03

Lean Left vs.Diagonal Right
males
5,40
$7.70 \underline{p}<.001$
females
5,40
$6,92 p<.001$

averaged rod fixation vs. lean left
rnales
5,40
$7.36 \mathrm{D}<.001$
females
5,40
$17.61 \mathrm{p}<.001$

averaged rod fixation vs. eyes open
males
5,40
.075
fernales
5,40
1.440 
Comparison SV

$d f$

$\mathrm{F}$

Visual Conditions (cont'd)
averaged rod fixation vs. eyes closed
males
5,40
1.32
fenales
5,40
.18

Males vs. Females

Eyes closed

Eyes open

Vertical Rod

Horizontal Rod

Diagonal Right

Lean Left
5,40 .032

5,40

1. 28

5,40 .067

5,40

.49

5,40

1.83

5, 40

$2.11 p<.10$ 


\section{EFFECTS OF VISUAL CUES ON THE STANDING}

BODY SWAY OF MALES AND FEMALES

A Dissertation

By

SEYMOUR WEISSMAN

Approved as to style and content by:

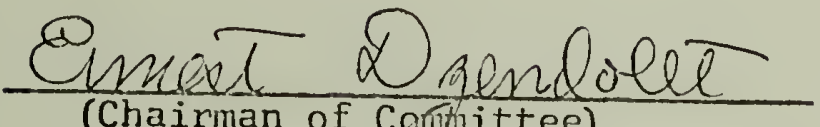

(Chairman of Coritititee)

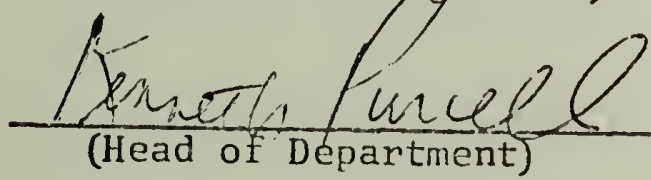

(Head of Department)
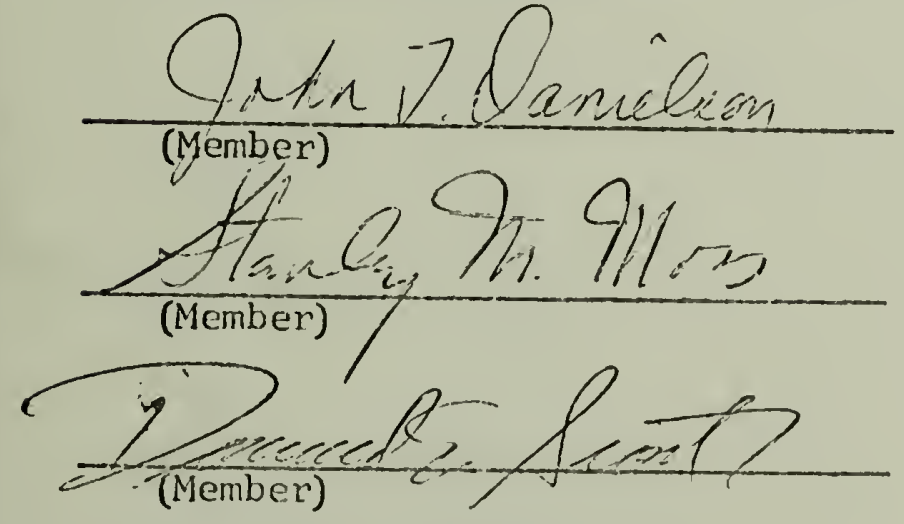

May, 1970 
Effects of Visual Cues on the Standing Body Sway of Males and Fenales (May, 1970)

Seymour Weissman, B. A., Hunter College M.A., Bowling Green State University Directed by: Dr. Ernest Dzendolet

In a standing position. six male and six female Ss were exposed to the following visual conditions: eyes closed, Iuminous rod vertical, luminous rod horizontal, lurinous rod diagonal rlght, eyes closed - body lean left, and eyes open with view of experimental room. Each $\underline{S}$ was tested in a single session, with the $1 \times$ conditions presented according to their position in a Latin square design. Each trial consisted of a 4 min. stimulus presentation period followed by 5 min. of rest. The response measure, recorded on one channel of a tape recorder, was whole body sway in the lateral direction. This measure was analyzed using the autocorrelation, the power spectral density, and analyses of varlance.

The conclusions from the present study were:

1. Lateral sway was only glightly affected by visual cues.

2. Visual fixation of luminous 11 nes in various orientations did not differ signiflcantly from eyes closed conditions, in thelr effect on lateral sway. In adition. 11ttle differences were noted in lateral sway as a function of rod orientation.

3. Ss tended to exhibit greatest stablilty (lowest overall powerl in the eyes open condition. This differences was more marked for female than male ss. 
4. In general, female so tended to be more stable (less overall power) than male Ss, and th1s difference was most evident in the eyes open and lean conditions.

5. Most of the power in Sa' sway was between 0.0 and $0.5 \mathrm{~Hz}$, whether or not Ss were being visually stimulated.

6. Those differences noted in body sway as a function of visual conditions were of the nature of overall changes in PSD level rather than any shifts of specific peaks of the PSD to new frequencies. 
